\title{
Árbitros de fútbol: ¿un c. elegans para la metodología de las ciencias sociales?
}

\author{
A. JAVIER IZQUIERDO \\ Departamento de Sociología I. \\ Facultad de Ciencias Políticas y Sociología. \\ Universidad Nacional de Educación a Distancia \\ jizquier@poli.uned.es
}

[A] pesar de la ausencia de exposiciones específicas de los métodos científicos, es evidente que los científicos no se sienten perdidos en cuanto a qué hacer en su trabajo. Hallan su camino a través de problemas singulares, discusiones vernáculas y rutinas de investigación organizadas, y lo consideran una competencia vulgar sobre los «hechos de la vida diaria». En otras palabras, no merece la pena hablar en el código del "método cientifico" sobre la mayor parte de lo que constituye de modo evidente el carácter ordenado y ordinario de las actividades científicas. Paradójicamente, es justamente esto lo que constituye la razón de ser de los estudios etnometodológicos: el hecho de que no exista motivo alguno para que las exposiciones genéricas de los métodos científicos se ocupen de las prácticas ordinarias mediante las que los científicos producen el carácter evidentemente cientifico de su trabajo cotidiano. (Lynch, Livingston y Garfinkel, 1995: 165).

El vídeo pretende posicionarse como un tercero mediador, situarse en la articulación de dos mundos: por un lado, el del juego y el de sus reglas, y por otro el de los espectadores y sus sentimientos de justicia e imparcialidad. Se trata de intento de introducir una realidad "científica» objetivista que pretendería abolir a la vez el estatuto del árbitro -considerado a la vez como factor lúdico siempre sometido a la incertidumbre de sus interpretaciones, y como el depositario de una consciencia capaz de representar el mundo real de los espectadores al sancionar las prácticas abusivas que desnaturalizan el juego-y el estatuto del espectador que objetiva y juzga la falta cometida por el infractor a partir no sólo de su competencia en la aplicación de las reglas del juego, sino también de su propia subjetividad y parcialidad en tanto que seguidor de un equipo. (Coulon, 1998: 26).

Pues, si quieren, que pite un robot. Pero aun así el que hace el robot también es humano. (Gamal Ghandour, árbitro de fútbol egipcio, en respuesta a las crí- 
ticas recibidas por su actuación en el partido Corea del Sur-España, de los cuartos de final de la Copa de Mundo de Fútbol 2002).

\section{INTRODUCCIÓN}

El largo reinado, en el campo de la filosofía y la metodología de las ciencias sociales, del retrato ideal-típico del proceso de razonamiento lógico de los grandes nombres de la física-matemática, desde Galileo y Newton a Maxwell y Einstein, tal como fue asentado por los textos clásicos de la filosofía de la ciencia publicados a fines de la década de 1950 y principios de los 60 (véanse aquí los tratados clásicos de Popper (1977 [1959]) y Nagel (1968 [1961]), como «material empírico de referencia» para la caracterización «programática» de las operaciones fundamentales de la investigación social (observación, deducción, inducción de causalidad, etc.), ha constituido un reflejo más bien pálido y particularmente fallido del método investigador, empleado desde hace casi dos siglos en los campos de la biología y la medicina, consistente en la realización de experimentos in vitro sobre modelos de organismos sencillos y estandarizados, como la legendaria bacteria escherichia coli. O, para un caso disciplinar más cercano, del papel metodológico fundamental que, en el campo de las ciencias cognitivas, desempeña desde hace más de tres décadas el estudio naturalista de un específico marco normalizado de percepción y razonamiento, como es el juego del ajedrez (Chase y Simon, 1973).

Durante las dos décadas siguientes, se institucionalizó en la academia de la filosofía de la ciencia el arte de la modelización lógica de la planificación y la realización de experimentos en física, preferentemente del estado sólido y en los casos más avanzados de los grandes experimentos de la física de partículas ${ }^{1}$. De nuevo, para el buen conocedor de los retratos humanos como el del «campesino polaco» realizado por William Thomas y Florian Znaniecki (1927) o el de los miembros de la «sociedad de las esquinas» de William F. Whyte (1955), la «novedosa» extrapolación, como modelos del trabajo de la investigación sociológica empírica, de los ejemplos imaginarios y más bien desabridos de «la velocidad punta alcanzada por una bola de madera que cae por un plano inclinado», "la temperatura media alcanzada por un gas confinado sometido a presión», "la carga del campo magnético que se genera alrededor de una bobina de cobre al paso de una corriente eléctrica», o «los valores de los premios en una lotería numérica obtenidos mediante la simulación informática de un proceso estocástico estacionario (proceso de Monte Carlo)», presentaban una visión más bien raquítica de su propia forma característica vita contemplativa.

1 Los textos clásicos son aquí los de HACKING (1996) y GaLISON (1987). Para una versión historico-sociológica canónica de este giro experimental de la filosofía de la ciencia cf. Shapin y SCHAFFER (1985). 
Propondré aquí que el estudio de los usos contextuales de la amplia gama de recursos linguiísticos, corporales y materiales que emplean los árbitros de fútbol ${ }^{2}$ para enjuiciar literalmente sobre la marcha la infinidad de casos prácticos que se les presentan a lo largo de un partido puede desempeñar, en el campo de los estudios sobre la metodología de la investigación social, un papel análogo al de ciertos modelos animales sencillos empleados en la moderna biología molecular para el estudio y la ingeniería de procesos de mutación controlados, como la popular «mosca del vinagre» droshopilla melanogaster o, más recientemente, el nemátodo (gusano) cahenorhabditis elegans, propuesto, en una serie de trabajos publicados a principios de 1960, como modelo experimental para el estudio de la diferenciación celular y la formación de órganos en vertebrados, por Sidney Brenner, insigne genetista de la Universidad de Cambridge y Premio Nobel de Fisiología y Medicina de 2002. A lo largo de la década de los 90 el modelo biológico $c$. elegans se convirtió en el banco de pruebas por excelencia de la nueva disciplina «estrella» de las ciencias naturales, la genética molecular de poblaciones, uno de cuyos logros más conocidos ha sido la culminación del Proyecto del Genoma Humano.

\section{EL TRABAJO DEL ÁRBITRO Y LOS ESTUDIOS ETNOMETODOLÓGICOS DEL TRABAJO}

Al hilo de la lectura de una pequeña muestra de los estudios etnometodológicos sobre los procedimientos de descubrimiento de la acción práctica que se llevan a cabo de forma rutinaria en el desempeño ordinario de un trabajo profesional (véase Garfinkel, 1986 y 1991; Izquierdo, 2003), me llamó la atención que, sobre todo al inicio de sus apartados introductorios, varios de estos informes empleaban de modo ilustrativo el ejemplo del «árbitro de fútbol que pita gol» para hacer ver con más claridad al lector en qué consiste exactamente la radicalidad de esos «fenómenos radicales orden social» que dicen estudiar los etnometodólogos. Así, por ejemplo, en su estudio sobre los procedimientos escolares de selección de alumnos discapacitados, Hugh Mehan presenta el ejemplo del árbitro de fútbol que sanciona un gol para llamar la atención sobre la forma como el informe del psicólogo educativo hace visibles las discapacidades de aprendizaje de un alumno (Mehan, 2001: 284). Por su parte, Charles Goodwin, en su estudio etnográfico sobre la organización social de la percepción de diferentes fenómenos científicos en el marco de la actividad investigadora desarrollada en un barco oceanográfico, compara la relación entre el "paisaje construido" del campo de fútbol y la sanción arbitral del gol, en tanto que jugada posible y visible dentro del mismo, con la forma como los gráficos que

${ }^{2}$ Desde una perspectiva sociológica que podemos llamar «clásica», el trabajo de los árbitros de fútbol sólo muy recientemente ha comenzado a ser considerado como objeto de estudio legítimo dentro de la subdisciplina de la Sociología del deporte. A este respecto, los investigadores del Centro de Investigación sobre Deporte y Sociedad de la Universidad de Leicester (RU) son pioneros (vid. COLWELL, 1998, 1999, 2000, 2001a y 2001b). 
se van dibujando en la pantalla de un ordenador, hacen visible al técnico oceanográfico que los lee con la vista, un nuevo campo fenoménico donde pueden desplegarse determinadas actividades prácticas que tiene como objetivo desplazar físicamente bajo la superficie oceánica un complejo y pesado instrumental de muestreo (Goodwin, 1995: 259).

Un tercer ejemplo puede encontrarse en el estudio de John Heritage y Steven Clayman sobre la variedad de sutiles recursos y procesos interaccionales observables en el trabajo de las entrevistas periodísticas a cargos públicos y personajes de la vida política realizadas en el contexto de los noticiarios televisivos. En la introducción metodológica, Heritage y Clayman introducen el ejemplo de cómo las técnicas de «moviola» empleadas por los realizadores de televisión en las retransmisiones deportivas son usadas, por el espectador para profundizar en su conocimiento de la jugada particular y el juego en general, como modelo pedagógico para exponer su propia versión de qué sea la «corrección metodológica» en la investigación sociológica mediante análisis de datos audiovideográficos:

«El valor de los datos obtenidos mediante audio-videograbación no puede ser minimizado. Una vez grabado, un segmento de interacción puede ser examinado de forma repetida, examinado de nuevo cada vez que se obtenga nueva información, e incluso ralentizado para una disección fotograma a fotograma. Por tanto puede ser analizado con mayor detalle y precisión de lo que sería posible si solamente pudiera ser observado una única vez en tiempo real. La importancia de los datos audiovideográficos en el análisis de conversación es la misma que tiene la «moviola» o repetición instantánea a cámara lenta en los eventos deportivos televisados. Mientras que los espectadores que están en la grada sólo pueden atrapar de modo vago los eventos en curso de una jugada cualquiera, los espectadores de televisión, en virtud de la moviola, puede alcanzar un entendimiento a la vez más profundo y más preciso de la secuencia específica de comportamientos que se combinan para producir el resultado de una jugada. Lo mismo vale para el estudio académico de la interacción humana cuando ha sido preservada en soporte de audio o video... Y al igual que los espectadores de television pueden usar la moviola para evaluar la precisión tanto de una decisión arbitral como de la evaluación de la misma que hace el comentarista de televisión, los lectores de análisis conversacionales pueden consultar los fragmentos de trascripción para evaluar el análisis realizado por su autor.» (Heritage y Clayman, 2002: 18-19) ${ }^{3}$.

Finalmente, el breve ensayo de Alain Coulon sobre la distinción entre «arbitrariedad» $\mathrm{y}$ «arbitrio» de los jueces deportivos, ofrece una serie de útiles apun-

${ }^{3}$ El simil pedagógico de las nuevas oportunidades de evaluación (y disfrute) que se le abren al espectador de partidos de fútbol televisados con la introducción, por parte de los realizadores televisivos, de procedimientos elaborados de repetición de jugadas interesantes (cámara lanta, ángulo inverso, etc.), como trasunto de los métodos específicos del análisis de la conversación, ya había sido empleado por J. Maxwell Atkinson en su estudio pionero sobre el lenguaje oral y corporal en los discursos públicos de los políticos profesionales (ATKINSON, 1986: 7-9). 
tes para el estudio etnometodológico del trabajo de los árbitros de fútbol —e.g. las reflexiones sobre el carácter ambivalente del uso de las tecnologías de videograbación, como valioso instrumental de apoyo que obstaculiza al mismo tiempo el progreso técnico de las competencias profesionales de los árbitros.

«Es cierto que la televisión objetiva el error. Antes de la era de la televisión, el espectador se quedaba con la duda y permanecía en ella. Hoy en día, con la multiplicación de los ángulos de visión, el recursos sistemático a la cámara lenta o "moviola" - verdadera puesta en escena de la dialéctica que vincula lo próximo y lo distante, lo visible y lo escondido, lo presente todavía no visto, las cosas vistas pero no tenidas en cuenta - permite revelar a ojos de todos la verdad de la acción, mostrando las trampas eventuales de los jugadores - en particular lo obtención fraudulenta de penaltis o de golpes francosy poniendo en tela de juicio sus intenciones aparentes. Esta tecnociencia desvela los errores de interpretación de la jugada cometidos por el árbitro. El error arbitral se convierte así en un "fallo"... mientras que, a la inversa, cada espectador se convierte, por intermediación de la imagen, en un árbitro todo poderoso, absoluto, que no se equivocaría jamás puesto que se haya asistido por la técnica.» (Coulon, 1998: 27).

Junto con los descubrimientos de la acción y el razonamiento prácticos llevados a cabo de forma ordinaria - luego invisible e insensible - como parte de la ejecución competente de las tareas rutinarias implicadas en el trabajo de investigación científica ${ }^{4}$ y el diseño tecnológico ${ }^{5}$, el tercer «híbrido laboral» al que la segunda y la tercera generación de alumnos de Garfinkel han prestado una atención especial ha sido el trabajo legal. En la estela del estudio clásico de Garfinkel sobre los métodos de razonamiento de sentido común que emplean los miembros de un jurado popular inmersos en un proceso de deliberación (Garfinkel, 1984 [1967]; Maynard y Manzo, 1993), se ha desarrollado durante la última década un cuerpo considerable de literatura empírica ${ }^{6}$ que describe la inteligencia de interacción conversacional y escrita de carácter local que demuestran poseer tanto los profesionales del derecho (abogados, procuradores, peritos, jueces, legisladores) como los ciudadanos legos que, en calidad de acusados, acusadores, testigos, jurados, espectadores presenciales $o$, más recientemente, público televisivo (Jasanoff y Lynch, 1998), han llegado a verse inmersos en las circunstancias históricas concretas de un proceso legal determinado.

\footnotetext{
${ }^{4}$ Los primeros estudios etnometodológicos sobre el trabajo versaron sobre diferentes disciplinas de las ciencias naturales, como la física (GARFINKel, LyNCH y LivingSTON, 1981), la neuroquímica (LYNCH, 1987) o las matemáticas (LIVINGSTON, 1986).

5 Los ethnomethodological studies of work han alcanzado sin duda sus mayores éxitos durante la década de los 90 en su hibridación disciplinar con diversas disciplinas del campo de la ergonomía, la ingeniería de sistemas de comunicaciones y la ingeniería de software. Véanse SuCHMAN (1987), AGRÉ (1998) y la colección de estudios recogida en LUfF, HiNDMARSH y HEATH (2000).

${ }^{6}$ Para una revisión actualizada, sintética y comprensiva de esta literatura cf. Travers (2001), y el volumen colectivo editado por TRAVERS y MANZO (1997).
} 
La de los árbitros de fútbol es una de las «comunidades de práctica» (Wenger, 2001) a la vez más interesantes y peor comprendidas (vid. Villalba, 2001a) ${ }^{7}$ dentro del universo general de las profesionales académico-legales, y en particular, de la profesión judicial. Considero, sin embargo, que el seguimiento microscópico, palmo a palmo, del modo como se configura y proyecta sobre el mundo la «visión profesional» del árbitro de fútbol, ofrece un «lugar transparente» ${ }^{8}$ desde donde observar de forma natural cómo se realiza de forma natural la universal capacidad alquímica de la acción humana para transmutar fenómenos de orden perceptivo en fenómenos de orden social.

Junto con esta virtud metodológica, el estudio «en tiempo real» del trabajo árbitral podría tener también una utilidad que me atrevería a calificar de cívica, más aun, humana: contribuir «un poquito» a defender a los miembros de la profesión arbitral contra las terribles consecuencias que en algunos casos puede llegar a producir la admisión, por los protagonistas y los espectadores del juego, de la estúpida fraseología al uso sobre la supuesta «naturaleza controvertida» de la «figura» o la «función» del árbitro de fúbol como una descripción exacta o fidedigna de la realidad del trabajo in situ e in vivo que llevan a cabo estos profesionales. En la mayor parte de los casos, el uso de este lenguaje explícitamente retórico y de raíz principalmente periodística - aunque también puede servir también como pie para las más abigarradas aventuras post-filosóficas (Verdú, 1980) - demuestra una total falta de comprensión del y, sobre todo, hacia el trabajo de los árbitros. El descrédito profesional a priori, generalizado y a veces incluso sin matices o paliativos que sufre la profesión arbitral en tanto que profesión ilegítima, está sin duda alguna, a mi juicio, en el origen del más pavoroso «efecto colateral» que pueda llegar a tener una actividad comunicativa que escapa por completo a la prueba de la realidad: la violencia física. No sólo dentro sino también fuera de los estadios de fútbol, jugadores, entrenadores, directivos y espectadores ejercen, cada fin de semana y con una impunidad que sólo puede calificarse de increible, todo tipo de acciones violentas, algunas absolutamente inhumanas en su tremenda brutalidad (como las «palizas colectivas»), sobre los más indefensos de entre los miembros del colectivo arbitral, esto es, la práctica totalidad de colegiados que arbitran en las categorías no profesionales del fútbol español (cf. Morenilla, 2002).

La tarea de juzgar en movimiento-juzgar el movimiento, es específica del trabajo de los árbitros de fútbol. Podemos definir el pitido del árbitro como una forma singular de expresión de la «visión» que proporciona la mejor «descripción» posible del hecho mismo que sanciona, a saber, que en un momento concreto del partido, en un lugar preciso del terreno, la continuidad del juego ha sido interrumpida por orden del árbitro como consecuencia de la transgresión de tal o cual regla por tal cual jugador. Tratamos aquí, evidentemente, con un tipo sui

7 Y tal vez por ello más controvertidas: según cierto «análista simbólico» del «imaginario futbolístico», la figura arbitral suele inspirar, tanto en los protagonistas del juego (jugadores y espectadores) como en los propios espectadores, sentimientos combinados de temor y odio (VERDÚ, 1980: 50-62).

${ }^{8}$ Perspicuous setting, en el sentido de GarfinKel (2002: 199-202). 
generis de documento público - pues su «sonido audible» se puede registrar y reproducir para su examen público- que, a la vez que la ocasiona, da fe de la transmutación de un suceso físico, el «gol real», una facticidad directa, visible por el ojo humano ${ }^{9}$ en una «cosa social»: el «gol legal» ${ }^{10}$.

Tal como se emplea en los estudios etnometodologicos del trabajo legal, la hipótesis de la descriptibilidad, analizabilidad y reflexividad naturales de las prácticas ordinarias, nos será también de gran ayuda en el siguiente trabajo preliminar: la especificación de las facultades distintivas que demuestra poseer un «miembro competente» cualquiera de la profesión arbitral para identificar, describir, explicar y justificar incluso las más ínfimas de las manifestaciones singulares no sólo del juego (es obvio que para arbitrar bien hay que saber mucho de fútbol; como lo es también, por ejemplo, para ser un buen realizador televisivo de partidos de fútbol) en sí sino también del trabajo de sus colegas ${ }^{11}$.

Aunque, dado que su trabajo implica de manera fundamental la necesidad de juzgar en movimiento -más exactamente «en carrera», los recursos clave de los que se sirve el árbitro para enjuiciar los casos que plantea continuamente el desarrollo del juego son capacidades y técnicas corporales como la resistencia fisiológica (Dip et. al., 1993; Johnston y McNaughton, 1994) o la «colocación» (Hagan, 1997), entre los rasgos pertinentes de un hipotético «retrato metodológico robot» de la excelencia profesional del arbitro de fútbol, podrían incluirse también, facultades intelectuales complejas como la capacidad de «cálculo lógico multicriterio» (Byrne, 1981 y 2000), atributos psicológicos especializados (e.g. «máxima tolerancia al estrés») (Taylor y Daniel, 1987; Bar-Eli et. al., 1995); o habilidades sociales extraordinarias como la plasticidad de carácter que exige el mantenimiento del delicado «balance de fuerzas» entre distanciamiento autoritario ${ }^{12}$ y empatía comunicativa (Burns, 1987) que permite al árbitro «controlar el partido» (Van Kolfschooten, 1998) ${ }^{13}$.

9 Vaya aquí una definición intencionadamente «legalista» de qué sea un gol real: «la relación espacial entre (1) el desplazamiento del balón entre los tres palos de la portería y hacia el interior de la misma (fenómeno cinético, él mismo, admitido a trámite legal por las "reglas del juego») y (2) una de las marcas físicas que delimita concretamente el terreno de juego donde se práctica este deporte - vgr. la "línea de gol" fina y rectamente trazada a lo largo de la franja de suelo que separa los dos postes verticales que sostienen la portería.»

10 Como correctamente ha apuntado, Alain Coulon el pitido del árbitro es un buen ejemplo de lo que los etnometodólogos llaman «reflexividad natural» - por tanto banal o carente de interés para los miembros implicados- de las prácticas sociales: la ocurrencia de un suceso que proporciona la descripción más adecuada de ese mismo suceso (Coulon, 1998: 32, ${ }^{\circ}{ }^{\circ}$ ).

11 Así, la introducción de una salvedad circunstancial en la interpretación convencional de las reglas del juego, el correcto manejo del tempo del partido en la administración de las sanciones o la forma de redactar una observación un lance menor del juego en el acta escrita del partido. La competencia de juicio se muestra también, o más bien sobre todo, en la correcta apreciación de las en apariencia más intangibles cuestiones de «estilo», como la manera de desplazarse por el terreno de juego, la forma de sostener la mirada cara a cara frente a un jugador desafiante o la «decisión», en el sentido de «convicción inequívoca», que trasmite el modo de hacer sonar un silbato.

${ }^{12}$ Para una investigación sobre los rasgos autoritarios de la personalidad arbitral, véase Aresu, Bucarelli y Marongiu (1979).

${ }^{13}$ La acumulación, a lo largo de las dos últimas décadas, de una multitud de pequeños cambios operativos en las «maneras» que muestran los árbitros sobre el terreno de juego, esto es, en los sig- 


\section{LOS MÉTODOS MUNDANOS DEL TRABAJO LEGAL Y EL SENTIDO COMÚN DE LA JUSTICIA}

En el marco de una conocida investigación llevada a cabo en 1957 sobre los métodos de investigación de la realidad social que emplean los jurados populares para alcanzar un veredicto, el sociólogo Harold Garfinkel (1984 [1967]), presentaba una serie de «observaciones fugitivas» que considero muy sugerentes desde el punto de vista de la específica problemática de los métodos locales de producción del orden social que se trata de clarificar aquí. Según Garfinkel, en primer lugar, los jurados se sienten incitados a modificar las reglas de decisión de sentido común que emplean en su vida diaria (reglas que, de un modo general, implican tanto el uso de todos aquellos conocimientos que la persona en cuestión posee en su cualidad de miembro competente de una sociedad como la inexistencia de un requerimiento de neutralidad o de «duda metódica») para tratar de cumplir con los dictados de la línea oficial de administración de justicia marcada por el juez (el veredicto debe basarse en la aplicación de principios formales de «objetividad» e «impersonalidad»; e.g. entre lo que es legal y lo que es justo el buen jurado elige lo que es legal; las decisiones de un buen jurado varían independientemente de sus simpatías personales, etc.)

«Las decisiones de la vida diaria en las que separamos los hechos de las fantasías no se hallan confinadas dentro de una preocupación exclusiva por encontrar una definición de la situación como razón en sí misma. Pero en la sala de deliberaciones, los jurados ciudadanos debe decidir exclusivamente

nos más visibles (como la distancia física, el gesto facial y corporal, y el tono de la voz) que modulan, expresándolas, sus competencias de interacción social, ha acabado por afectar al nivel más profundo del modelo de comunicación arbitral: el de sus fundamentos éticos. Como ha sido señalado recientemente por un colegiado de 1. ${ }^{\text {a }}$ división en ejercicio: «Hace 20 años, la forma de arbitrar era más autoritaria, pero el jugador ha de entender que no le ofendemos. Hemos de transmitir tranquilidad, no nerviosismo.» (Antonio Llonch Andreu, árbitro de 1. a división, citado en Villalba, 200lb). «[En un árbitro] el no decir absolutamente nada puede manifestar independencia o puede interpretarse como conducta defensiva. Muchas veces, dar muchas explicaciones puede significar justificación, que tampoco se considera adecuado porque el árbitro no ha de dar justificaciones de nada. Creo que lo adecuado es el término medio: hablar pero sólo lo justo.» (Manuel López Fernández, experto en psicología del arbitraje de la recientemente creada Escuela Nacional de Árbitros, en Villalba, 2001b). Si bien es en las operaciones de «especificación física» que exige el paso de la teoría a la práctica del "control del partido" donde cabe localizar el conjunto definitivo de indicios, pistas, signos y marcas convencionales que, desde el punto de vista de los propios árbitros, permiten identificar la «excelencia arbitral» allí donde se muestra. Así, por ejemplo, en el delicado terreno de la acción sancionadora, la receta teórica que recomienda buscar el equilibrio entre actitud comunicativa y distanciamiento autoritario tiene en el empleo de márgenes estándares (e.g. entre metro y medio y dos metros) de «distancia de seguridad-cortesía» entre el árbitro y el jugador a sancionar su parámetro de implementación más tangible. «[H]ay que evitar la ira y la arrogancia al mostrar una tarjeta. Lo que se sancionan son acciones, no se castiga a las personas... La distancia ha de ser adecuada para no invadir el espacio íntimo. Lo ideal es un metro y medio o dos metros. Es suficiente para que el jugador se dé por aludido. ¿Y cómo? Con un gesto claro, sin lanzarle la tarjeta a la cara ni ofenderle.» (López Fernández, en Villalba, 2001b) Por otro lado, la capacidad de «control del partido» es sin duda la cualidad arbitral más apreciada por jugadores y entrenadores (Hill, 1977). 
cual era la situación como una cuestión de hecho en sí misma... Es la clarificación de los fundamentos de la elección de un veredicto como una razón en sí misma lo que constituye el propósito específico de la investigación del jurado... En una palabra, se pide al jurado que trata la situación como un objeto de interés teórico.» (Garfinkel, 1984 [1967]: 111).

Sin embargo, las grabaciones de las deliberaciones que efectivamente tienen lugar en la sala del jurado, muestran que las modificaciones que efectivamente realizan los jurados sobre sus rutinas prácticas de conocimiento de sentido común son muy pequeñas y tienen como resultado un situación de elección marcada por la ambigüedad. Garfinkel concluye, finalmente, que la actividad de un jurado se define en mayor medida por la gestión de dicha ambigüedad que por la «juiciosidad» de sus decisiones.

«Sugerimos, conjeturalmente, para concluir, que en vez de concebir al miembro sofisticado del jurado como una replica lega del juez, sea concebido como una persona lega quien, cuando ocurren cambios en la estructura y las operaciones del jurado, puede alterar los fundamentos de su decision sin sufrir confusión alguna en cuento a sus expectativas de respaldo social por lo que habrá hecho.» (Garfinkel, 1984 [1967]: 115).

Diversos aspectos de los sistemas de justicia deportiva, en particular la función judicial sui generis que desempeñan los árbitros de fútbol, ofrecen posibilidades investigadoras estratégicas para verificar empíricamente la hipótesis del sentido común de la justicia ${ }^{14}$. En particular, el estudio de las «huellas indiciarias» (Ginzburg, 1992) sobre las que se construye el arbitrio arbitral (marcas espaciales, síntomas psicológicos, gestos de comunicación no verbal, "pistas» temporales, etc.) ofrece un banco de pruebas muy adecuado para contrastar la validez empírica de diferentes modelos teóricos (filosóficos, sociológicos, jurídicos, filosófico-jurídicos y jurídico-sociológicos) de la articulación entre el dominio de la tecnología legal disponible y competencia interpretativa «de sentido común», en la formación del juicio legal. Y más en particular aún, los estudios legales materiales sobre el concepto de «arbitrio judicial» (Nieto, 2000) podrían beneficiarse extraordinariamente de un trabajo de explicitación de algunos de los más sencillos contenidos locales de la excelencia profesional en el mundo del arbitraje futbolístico (véase infra sobre el trabajo arbitral de «indicar la distancia correcta»).

${ }^{14}$ Es esta una facultad de juicio cuyo ejercicio difícilmente puede ser monopolio exclusivo de una comunidad de expertos o especialistas. En la sociedad política de carácter democrático la capacidad de formular críticas morales el comportamiento de los demás posee un carácter eminentemente plural. $\mathrm{O}$, lo que es lo mismo, los ciudadanos pueden apelar a diferentes principios superiores convencionalmente admitidos, como el interés, la eficiencia o el civismo, para legitimar públicamente sus juicios de valor individuales. La dimensión plural del juicio moral está, finalmente, en la base de dos fenómenos fundamentales de nuestra vida pública: la disputa y el acuerdo. Para la formulación original de la hipótesis del sentido común de la justicia cf. ARENDT (1995 [1971]). Véanse también Boltanski y THÉvenOT (1991) y BolTANSKI y CHIAPELlo (2002: cap. VI). 
La cuestión fundamental de la racionalidad procedimental (Simon, 1986); de los métodos legales de toma de decisión, tal como ha sido explícitamente planteada, por ejemplo, como subproducto de una serie de iniciativas recientes tendentes a institucionalizar la práctica del control automático del trabajo judicial ${ }^{15}$, podría efectivamente iluminarse mediante un seguimiento del debate paralelo que se viene planteando desde hace unos años en el seno de los máximos organismos futbolísticos internacionales (FIFA, UEFA) sobre el uso de prótesis videográficas para objetivar las decisiones arbitrales (búsqueda legítima de un plus de precisión que estaría amenazada, según sus críticos, por la quiebra de la continuidad característica del juego, de la que emana buena parte de su carácter espectacular) ${ }^{16}$.

En la tradición dogmática de la ciencia jurídica ${ }^{17}$, el arbitrio judicial se entiende como el ejercicio inexcusable, motivado por el carácter incompleto de toda norma escrita, de una capacidad experta de interpretación y justificación en los huecos, intersticios y fronteras de la literalidad legislativa (Nieto, 2000: 219$270)^{18}$. En el espacio propio de su competencia profesional, el juez ha de emplear, en primer lugar esquemas cognitivos eficaces para seleccionar, valorar y componer narrativamente los hechos pertinentes del caso a partir de los testimonios orales y pruebas materiales presentadas durante el juicio (Nieto, 2000: 8190). También ha de dotarse de criterios heurísticos adecuados para llevar a cabo de forma a la vez ajustada y económica el trabajo de localización y selección de textos y normas legales aplicables al caso (Nieto, 2000: 92-103). Y en última instancia ha de servirse de fórmulas conceptuales (doctrinas y teorías legales) adecuadas para identificar y ponderar con exactitud aquellos argumentos lógicos, causales o morales que mejor pueden «motivar» jurídicamente su decisión (Nieto, 2000: 153-199). Pero, en última instancia, solo cuando su ejercicio es «naturalmente descriptible» en términos «racionales», esto es, sólo cuando su

${ }^{15}$ En algunos sistemas de common law, como el australiano y el neozelandés, se halla extendida la práctica de equipar tecnológicamente las sentencias judiciales con tests informáticos de consistencia lógica. Según sus valedores, estos dispositivos de apoyo informático garantizan una mayor credibilidad pública de las decisiones judiciales (Zeleznikow, 2000). Si bien, según sus críticos (HENHAM, 2000; CYRUS, 2000), al coste de pérdidas inadmisibles de flexibilidad interpretativa.

${ }^{16}$ En última instancia, frente al dominio casi exclusivo que ejercen el sistema de oposición y los cursos de formación como métodos de evaluación y ampliación de la competencia profesional en el mundo judicial, el campo del arbitraje futbolístico parece exhibir una gama mucho más amplia y flexible de mecanismos de control (pruebas físicas y técnicas), supervisión (informes de actuación) y mejora (cursos de formación, seminarios prácticos) de la calidad del capital humano. El específico «sentido arbitral» de la justicia, con sus atributos corporales, intelectuales y morales característicos, es la pieza insustituible que, además del buen funcionamiento del engranaje reglamentario encargado del ordenamiento del juego, garantiza también el correcto reglaje competitivo del mecanismo administrativo encargado del progreso meritocrático de la profesión arbitral (cf. PALOMAR, 2000).

17 Para una introducción básica a los métodos de interpretación y razonamiento jurídico véase ATIENZA (1993: 23-32). Un autorizado análisis alternativo de la objetividad de los métodos judiciales desde el punto de vista de la teoría social de la acción comunicativa es el de HABERMAS (1998: 263-309).

18 Véase asímismo JONSEN y TOULMIN (1988) para una exposición del método de veridicción de los casuistas europeos del XVI y el XVII, venerable ancestro de las modernas teorías «pragmáticas» del arbitrio judicial. 
proceso de razonamiento puede ser, de algún modo, «examinado a la luz pública», puede el arbitrio judicial sustraerse efectivamente a la crítica clásica contra los excesos voluntaristas de los operadores jurídicos - la acusación de arbitrariedad - y producir una decisión consistente con el «espíritu» de la ley (Nieto, 2000: 290-310).

Y es justamente desde el punto de vista de este atributo distintivo, el de ser no sólo un procedimiento de juicio sino un procedimiento público, que comparte con el arbitrio arbitral, que puede sostenerse que un conocimiento exhaustivo y detallado de las «condiciones de felicidad» de la justicia deportiva que imparten los árbitros de fútbol ha de arrojar necesariamente nueva luz sobre la controversia clásica en la dogmática jurídica Occidental en torno a lo que podríamos llamar la «robustez científica» del arbitrio judicial.

\section{EVALUACIÓN DEL DESEMPEÑO: DE LOS FORMULARIOS ESCRITOS A LAS CINTAS DE VIDEO}

«Mientras yo sea presidente de la FIFA, estoy totalmente opuesto a la ayuda artifical a los árbitros en los partidos controlados por la FIFA» (Joseph Blatter). «Las repeticiones de vídeo no son la solución. Si introducimos la televisión para chequear si la pelota cruzó o no la línea de meta, tendríamos que usarla también para determinar las faltas, los fuera de juego y los penalties. Imposible.» (Michel Platiní, ex-jugador francés, asesor del Comité Técnico de la FIFA) ${ }^{19}$.

Al comienzo de la Fase Final del Campeonato Mundial de la Federación Internacional de Fútbol Asociación (FIFA) del año 2002, organizado por Corea del Sur y Japón, algunos medios de comunicación general se hicieron eco de las quejas formuladas por algunos de los colegiados internacionales seleccionados para actuar en el torneo que tenían como blanco una curiosa autorización referente al uso de los videomarcadores de los estadios que, según los colegiados, era contraria no sólo al espíritu de las declaraciones programáticas al uso de los altos dirigentes de FIFA sobre la indeseabilidad de las ayudas videográficas al trabajo arbitral, sino también a los reglamentos vigentes de la Asociación. La autorización en cuestión, concedida por FIFA al organismo organizador del campeonato, permitía que se mostrasen en los videomarcadores de los estadios sede del Mundial imágenes de lo que ocurría sobre el césped durante la disputa del partido.

«Esta decisión... puede tener un profundo efecto sobre lo que sucede en los estadios, tanto en las gradas como en el terreno de juego. Por ejemplo, ise pueden generar altercados en las tribunas por la emisión de determinadas imágenes?, ¿un error proyectado en pantalla gigante puede afectar a las decisiones del árbitro?, ¿pueden volverse más inestables los jugadores si todo lo que sucede en el césped se observa por parte de miles de espectadores?, ¿qué imágenes son merecedoras de ser ofrecidas y cuáles no?, ¿quién lo decide y por

${ }^{19}$ Cf. «La FIFA rechaza el uso del vídeo para ayudar a los árbitros», Reuters (Londres), 8 de octubre de 2002 (noticia accesible en www.arbitrosdefutbol.com.ar) 
qué?... Durante los últimos años, la FIFA ha prohibido la emisión de cualquier imagen de los partidos en los estadios, de manera que los videomarcadores se han convertido en un [mero] vehículo de publicidad. El conflicto ha surgido en el Mundial por el enorme desembolso [hecho por] Japón y Corea en sus campos [para] dotarlos de las soluciones tecnologicas más novedosas. Unos recintos impresionantes que, en la mayoría de los casos, sólo albergarán dos o tres partidos. Para los proveedores de los videomarcadores el negocio era ruinoso. A ese punto se refirió explícitamente Cooper cuando admitió que la FIFA había sido tan sensible a las presiones de las empresas que se las había permitido el uso de las imágenes en directo. Cooper añadió un argumento que hasta el momento no ha servido en Europa: «No parece posible privar a una persona de ver las imágenes en los estadios cuando se ha gastado entre $60 \mathrm{y}$ 100 dólares por una entrada mientras el resto de los aficionados pueden ver por televisión lo que ocurre y las repeticiones desde mil ángulos diferentes. Y sin gastarse un céntimo». La decisión de permitir las imágenes en directo ha puesto a la FIFA ante otra disyuntiva. ¿Qué se emite y quién lo decide? Llegado el caso, los realizadores de televisión podrían convertirse en superárbitros al decidir qué jugada se ofrece y cuál no. Ante esta reflexión, la FIFA ha preferido que en los estadios se vea lo mismo que en la televisión.» (Segurola, 2002).

Durante el partido entre Inglaterra y Suecia, el videomarcador que emitía las imágenes del encuentro tuvo que ser apagado en el minuto 15 a causa, según explicó Keith Cooper, portavoz de la FIFA, del «miedo a que los hinchas encontraran una excusa para protagonizar actos de violencia dentro del estadio.» Por otro lado, las primeras reacciones de los árbitros tampoco fueron favorables a la medida. El árbitro del encuentro inaugural, el kuwaití Pujsaim, se quejó de la decisión de la FIFA: «Nos compromete en nuestro trabajo» (cursivas mías). En términos similares aunque más gráficos se expresaba también el árbitro internacional argentino Gabriel Brazenas: «Desde el día que en un partido entre Lanús y Boca conté 25 cámaras de un lado y 33 del otro, me dije: «Basta, no puedo competir». Yo tengo dos ojos y encima no tienen zoom. Algo me tiene que encontrar la televisión.» 20

Afirmaciones como las anteriores, proferidas por árbitros de nivel internacional, son muy interesantes, pues, de hecho, el principio normativo implícito en el procedimiento administrativo interno empleado, por ejemplo, por los Colegios de Árbitros federativos españoles, conocido como «Informe de Actuación Arbitral», en tanto que establece que la curiosa labor judicial que desempeña el arbitro de fútbol dentro de un terreno de juego sólo puede ser correctamente evaluada por sus pares $^{21}$, excluye radicalmente la posibilidad de

${ }^{20}$ Cf. «Los árbitros internacionales Sequiera, Pezzota, Brazenas y Martín reflexionan sobre los aspectos de su actividad», diario LA NACIÓN, Buenos Aires, viernes 14 de febrero de 2003 (noticia accesible en www.arbitrosdefutbol.com.ar).

${ }^{21}$ Más exactamente, por un colega retirado. o inactivo - al que suele denominarse "informador" o "delegado de partido"- que presencia in situ, desde la grada, la labor del árbitro en activo. La edad de 'jubilación deportiva' de los árbitros es un factor determinante de la oferta de recursos humanos para tareas de evaluación interna. Según la norma internacional en vigor de la Federación 
llegar a «compromisos» potencialmente «comprometedores» con «espectadores entrometidos».

El informe de actuación que debe cumplimentar el informador del colegio arbitral consta de dos partes: un extenso cuestionario tipo test compuesto de indicadores técnicos, físicos, psicológicos y prácticos que se correlacionan con aspectos positivos y negativos de la labor arbitral; y una parte escrita donde el informador ha de justificar de forma razonada las puntuaciones globales otorgadas en cada uno de los grandes apartados en los que se divide el cuestionario (personalidad y autoridad, juego brusco, faltas, condición física, colocación, etc.). Este elaborado sistema de revisión por pares es similar en muchos aspectos al empleado por los comités editoriales de las revistas científicas para evaluar resultados de investigación originales. Según una lógica supervisora análoga a la imperante en el mundo investigador, la selección de los informadores arbitrales se hace en base a criterios de categoría y antigüedad, los informes han de recibir el visto bueno del Comité Técnico y, así como los autores de un artículo remitido a una revista científica reciben una copia del informe de evaluación de los revisores, también el colegiado examinado recibe una copia del informe de actuación.

Pero sucede que, a diferencia de otros ámbitos profesionales, como por ejemplo el periodismo, donde la constelación de cualificaciones laborales que han de demostrar poseer sus miembros está claramente sesgada en favor de un núcleo estable de competencias cognitivas y morales (Lemieux, 2000), y donde, por tanto, la descriptibilidad natural de los documentos escritos posee un carácter «apropiado» desde el punto de vista de la práctica del trabajo, crítico, de evaluación de esas competencias, el sentido de la justicia deportiva que demuestran poseer los árbitros de fútbol no puede hacerse inteligible a personas «legas» en ausencia de un esfuerzo específico - y propiamente reflexivo- de trabajo corporal. Lo cual explica, por ejemplo, los malentendidos que suele provocar una transposición mecánica de la teoría legal del juicio al ámbito de la justicia deportiva ${ }^{22}$.

Internacional de Fútbol Asociación (FIFA), la edad límite para ejercer la práctica del arbitraje se establece en $\mathbf{4 5}$ años. La justificación sustantiva de esta norma se apoya en consideraciones fisiológicas estándares sobre el umbral de madurez biológica a partir del cual comienza a declinar, en promedio, el desempeño humano en la práctica deportiva.

${ }^{22}$ Los problemas prácticos que plantea, a los representantes de la justicia llamada «ordinaria» (jueces y magistrados), el reconocimiento del carácter sui generis y, por tanto, el interés metodológico-legal de la «justicia deportiva» tal como la imparten los árbitros de fútbol dentro de los terrenos de juego, han sido puestos de manifiesto por el fenómeno, cada vez más frecuente, del recurso a los tribunales civiles y penales por parte de clubes de fútbol en desacuerdo con alguna de las decisiones contenidas en el acta arbitral de un partido de fútbol (eg. la expulsión de un jugador, la suspensión del partido, la constatación de diversos incidentes extradeportivos que puedan ser motivo de clausura del estadio, etc.) que puedan tener un grave impacto negativo sobre la economía del club (véase GARDNER, 1997). De un fenómeno inverso y no menos interesante da cuenta una curiosa noticia aparecida recientemente en la sección de deportes de un diario nacional: la comisión permanente del Consejo General del Poder Judicial (CGPJ), brazo ejecutivo del principal órgano rector de la profesión judicial «real» dentro del Estado Español, denegó a uno de sus miembros - el magistrado Lorenzo Pérez San Francisco, de la sección civil de la Audiencia Pro- 
Este es también, sin duda, el motivo por el que las distintas administraciones de justicia deportiva han sido pioneras en el uso del video a la vez como documento y como método de análisis legal. En efecto, a lo largo de los últimos veinte años, las grabaciones videográficas han comenzado ha ser adoptadas como pruebas suplementarias, más bien que como sustitutos naturales de la documentación textual, en las deliberaciones del Comité de Competición de la Federación Española de Fútbol, que sigue la senda marcada por el Comité Internacional de FIFA que, si bien se opone a incorporar la tecnología de televisión para adoptar decisiones sobre jugadas en línea de gol declara lícito el uso de vídeocámaras para «cuestiones disciplinarias» — «bien para castigar a un jugador por una infracción no vista por un árbitro o para señalar la inocencia de un fubtolista.» ${ }^{23}$

De este modo, aunque con cierto retraso, los métodos profesionales de apreciación y enjuiciamiento de las jugadas de un partido de fútbol empleados por los espectadores y los comentaristas de televisión ${ }^{24}$, como la legendaria «moviola», han acabado siendo abrazados por el estamento judicial de la más poderosa de nuestras jurisdicciones deportivas. (Sólo algún tiempo más tarde los documentos audiovideográficos han comenzado también ha ser ya, literalmente, «admitidos a trámite» dentro de la esfera procedimental de la justicia llamada «ordinaria», esto es, la Administración de Justicia o la Justicia Legal con mayúsculas) ${ }^{25}$.

vincial de Madrid - el permiso para compatibilizar su trabajo «ordinario» en el juzgado civil con una labor «extraordinaria» como Presidente del Comité de Disciplina Deportiva de la Real Federación Española de Fútbol. La noticia hace referencia a una decisión anterior de carácter similar, recogida en un informe del Servicio de Personal del CGPJ, en la que se justificaba la denegación de compatibilidad a un juez de un Juzgado de Primera Instancia de Tarragona para ejercer una vocalía en el mismo Comité de Competición mediante el oscuro argumento escolástico de que «las funciones sancionadoras o disciplinarias de los comités de competición [deportivos] caen en el ábmtio de "decir el derecho", aunque sea a través de órganos no integrados en el poder judicial.» La decisión refiere asimismo al artículo 389 de la Ley Orgánica del Poder Judicial declara incompatible el cargo de juez o magistrado «con el ejercicio de cualquier otra jurisdicción ajena a la del poder judicial.» (cf. «Incompatible por ser juez. El Poder Judicial deniega al presidente de Competición ejercer el cargo", diario EL PAÍS, Madrid, 5 de marzo de 2003, 50).

${ }^{23} \mathrm{Cf}$. «La FIFA se opone al uso de videocámaras en la línea de gol», Reuters (Belfast), 18 de marzo de 2003 (noticia accesible en www.arbitrosdefutbol.com.ar).

${ }^{24}$ Sobre la «crítica profesional» del arbitraje futbolístico, tal como la llevan a cabo los comentaristas deportivos que «conducen» las retransmisiones de partidos de fútbol en televisión, véase COLWELL (2001b).

${ }^{25} \mathrm{Ha}$ sido en primer lugar el derecho procesal el que ha consagrado el uso de grabaciones audiovideográficas como evidencias probatorias: tanto grabaciones de tipo «circunstancial» (secuencias extraidas de emisiones de televisión, tomadas por cámaras de vigilancia permanente o bien filmadas casualmente por videoaficionados) como, con posterioridad, de carácter expresamente procesal («testimonios orales» de acusados, testigos o expertos grabados en vídeo). Sobre la controversia en torno a la legitimidad y, en su caso, la reglamentación de los "video-juicios», tal como se ha planteado a lo largo de los últimos años dentro de la tradición legal del common law anglo-americano, así como sobre las interesantes analogías y perversas conexiones entre el derecho procesal y el derecho de la propiedad intelectual que ocasiona la sustitución, durante la vista oral de un juicio, de la actuación (performance) in vivo e in situ de una 


\title{
5. «TOMAR MEDIDAS» COMO PRÁCTICA PÚBLICAMENTE ATESTIGUABLE: LA «DISTANCIA REGLAMENTARIA» IN VIVO E IN SITU
}

Traeré aquí, para finalizar esta parte, una muestra preliminar del modo como el estudio detallado de breves secuencias de video que documentan «en tiempo real» el trabajo de juzgar in vivo que llevan a cabo los árbitros de fútbol, puede contribuir a «desvelar» —o más a «re-descubrir»- algunos de los secretos peor guardados de profesionales del derecho menos incomprendidos. Sea, por ejemplo, la siguiente cláusula legal (13.1.1.1.1) en la que se especifica por escrito uno de entre los muchos pormenores a los que está sujeta la aplicación en la práctica de una de las 17 reglas de las que constaba el nuevo reglamento deportivo emitido en el año 2000 por la Federación Internacional de Fútbol Asociación FIFA:

\author{
Regla 13. Los tiros libres. \\ 13.1. Posición en el tiro libre. \\ 13.1.1. Tiro libre directo o indirecto en favor del equipo atacante. \\ 13.1.1.1. Tiro libre fuera del área de penal \\ 13.1.1.1.1. Todos los adversarios deberán \\ encontrarse como mínimo a 9,15 \\ m del balón hasta que esté en \\ juego. (Ramos Marcos, 2001: \\ 269).
}

Como cualquier otra norma legal de carácter específico, la cláusula subrayada en negrita, ha sido objeto de los más diversos comentarios de carácter tanto

persona (acusado, testigo, abogado o incluso el juez mismo) por su registro audiovideográfico, véase AUSLANDER (1999). En segundo lugar, la administración de justicia ha comenzado a hacer también un empleo extensivo del vídeo como tecnología de archivo: la Ley 1/2000 de Enjuiciamiento Civil, que entró en vigor en enero del año 2001, se establece la obligación de grabar en video las vistas que se celebren en todos los juzgados de Primera Instancia. La ley obliga asimismo a implementar en los juzgados nuevos sistemas de bases de datos basados en el tratamiento informático de imágenes videográficas, para fines de archivo, catalogación y consulta de las grabaciones llevadas a cabo en cada juzgado (ZUÑIGA, 2002). Esta función secundaria, meramente burocráctica, del vídeo como formato documental «de respaldo»no es sino el exacto reverso del uso «profano» (vgr. comercial) de los procesos judiciales como espectáculos televisivos, esto es, el fenómeno, historicamente anterior, de la emisión televisiva de las «jugadas más interesantes» - por utilizar un símil futbolístico que encuentro muy apropiado para el caso-_ de la vista oral de ciertos juicios «estelares» (eg. el llanto de un acusado durante el interrogatorio del abogado de la acusación o la lectura del veredicto final por parte del juez). Aunque las emisiones televisivas de sesiones judiciales «en directo» datan al menos de 1964 (el juicio contra dirigente nazi Eric Eichman celebrado en Jerusalem), no fue hasta la década de 1990 que llegaron a alcanzar el climax de los records de audiencia - en el caso de EE UU, con el juicio contra la estrella televisiva O.J. Simpson celebrado en 1995 y, en nuestro país, con la cobertura informativa diaria de las sesiones del juicio del llamado «caso de las niñas de Alcácer», celebrado en 1997 (PÉrez Abellán, 2002). 
«dogmático» como «doctrinal» o «jurisprudencial» ${ }^{26}$. Así por ejemplo, la doctrina al uso de la FIFA especifica que, una vez «indicada la falta y establecida su dirección», el arbitro debe procurar que "ningún jugador del bando infractor» se sitúe a una distancia de «menos de $9,15 \mathrm{~m}$ del lugar donde se produjo aquélla». Los órganos judiciales competentes para resolver diferencias interpretativas al respecto de la aplicación de esta norma han asentado asimismo un criterio objetivo para determinar el lugar desde el que deberá ser ejecutado el tiro libre, y que ha de ser «sobre la línea frontal del área de meta paralela a la línea de meta en el punto más cercano al lugar donde se cometió la falta.» Para «contar» la distancia el arbitro empleará como patrón de medida la extensión de su propia zancada, y procederá caminado en línea recta, a pasos iguales, desde el punto donde ocurrió la falta y hasta el punto donde alcanzare la distancia «reglamentaria».

«La medida de la distancia [a la que debe colocarse la barrera] debe hacerse con el lógico sistema que la FIFA aconseja: caminar deprisa hacia atrás, ligeramente ladeado, sin perder de vista el balón, y al llegar al punto estimado como bueno, extender el brazo correspondiente de forma que la barrera se alinee con la extensión.» (Ramos Marcos, 2001: 261) ${ }^{27}$.

Finalmente, los órganos judiciales competentes indican también de manera aparentemente "precisa» cual ha de ser el comportamiento del árbitro ante el caso, demostrado «muy frecuente» por la experiencia, de que «un jugador del equipo contrario al que efectúa un saque no se encuentre a la distancia reglamentaria.» ${ }^{28} \mathrm{Y}$ el criterio normativo establecido como relevante a este respecto es éste:

«Se le indicará la distancia correcta.» (Ramos Marcos, 2001: 269)

La correspondencia entre esta instrucción y uno sólo de los infinitos ejemplos de comportamiento humano concreto que permite describir, será el verdadero objeto de nuestra investigación en este punto.

Con el fin de contribuir a «calibrar jurisprudencialmente» el grado de precisión que posee esta última directiva cuando se la supone aplicada en circunstancias reales, presento a continuación un extracto de transcripción extraído del análisis de un documento televisivo más extenso, en el que se pone de manifiesto el

${ }^{26}$ Para una compilación de algunos de estos comentarios legislativos véase RAMOs MARcos (2001: 257ss).

${ }^{27}$ Que el procedimiento de medida que haya de emplear el árbitro aquí sea visiblemente «antropomórfico», no cambia en nada el fondo de la cuestión. Para la historia, necesariamente inconclusa y más bien decepcionante, de las teorías y los instrumentos científicos empleados para determinar distintos tipos de constantes metrológicas «fundamentales», consúltense KULA (1980) y MIROWSKI (1992). Para un conjunto de sugerentes formulaciones térico-metodológicas en torno a la semántica sociológica y la pragmática político-administrativa de la expresión «tomar medidas», véase IBÁÑEZ (1985).

${ }^{28}$ RAMOS MARCOS, La ley del fútbol, op. cit., 269. 
modo situado cómo un árbitro cumple en la práctica la mencionada recomendación doctrinal sobre el modo de aplicar una de las cláusulas secundarias de la Regla 13 del juego del fútbol según la FIFA. Se trata de una secuencia de poco más de 4 minutos de duración que fue emitida hace unos años en la sección $L o$ que el ojo no ve del informativo deportivo El día después emitido por la cadena de televisión Canal $+{ }^{29}$.

«Una vez [en El ojo no ve] le colocamos un micrófono a un árbitro, a Pajares Paz. Quisimos acercar el árbitro al gran público. Fue en un partido Atlético de Madrid-Deportivo de La Coruña y es uno de los documentos de los que más orgullosos nos sentimos [...] Permitimos que Pajares Paz lo editara, junto con nosotros, antes de salir a antena, pero apenas quitó nada, sólo lo que se oía mal.» ${ }^{30}$

\section{Secuencia . El árbitro y la barrera [d $=24$ segs]}

((Plano 1: primer plano de la barrera de cuatro hombres en el centro de la imagen. De izquierda a derecha: 8 , de frente mirando hacia la izquierda de la imagen, 9 , vuelto hacia la derecha, tapado por 5 que mira también hacia la derecha, finalmente 6 completamente de espaldas. La cabeza de A asoma entre el cuerpo de 8 y el de 9$)$ )

((Se escucha un fuerte rumor de fondo producido por los gritos de los aficionados que están en las gradas del estadio))

${ }^{29}$ Lo que el ojo no ve es un formato híbrido entre la filmación clásica «explícita» o «a cámara descubierta» y el truco de la «cámara oculta». El espacio pretende mostrar al espectador de TV el inagotable catálogo de comportamientos «privados» que tienen lugar dentro de una clase muy peculiar de espacio público: los estadios de fútbol. En la primavera del 2001, como conmemoración del décimo aniversario de la exitosa puesta antena de este espacio, se puso a la venta una cinta de vídeo de $1 \mathrm{~h} .20 \mathrm{~m}$ de duración que contenía una selección de escenas emitidas previamente dentro de este espacio. El vídeo se comercializaba conjuntamente con un libro en el que el periodista deportivo y ex-futbolista profesional inglés Michael Robinson comentaba por escrito las escenas recogidas en la cinta. De esta cinta de vídeo está extraída la secuencia que analizo aquí. Aunque no han recibido todavía el visto bueno «total» de los organismos federativos internacionales, este tipo de experimentos televisivos, llevados a cabo cada vez en mayor numero por cadenas de distintos países, que consisten en emitir, como parte de los contenidos de un partido de fútbol, el sonido directo, captado mediante micrófonos portados por los propios colegiados, de las conversaciones entre árbitros y jugadores, han sido calificados por la crítica periodística y deportiva, como el inicio de una verdadera «revolución» en el modo de «acercar» este juego al espectador de televisión (Morenilla, 2003). Opinión esta que parecen compartir tanto los profesionales televisivos ( «Por medio de Lo que el ojo no ve intentamos humanizar la imagen del árbitro... [y] comprender la relación que tiene el árbitro con los futbolistas» [Robinson, Lo que el ojo no ve, op. cit., 99]), como por directivos de los clubes profesionales («Es extraordinario. En 90 minutos el fútbol ha pasado del cine mudo al sonoro. Ha entrado en una modernidad con tal evidencia que parece que ya no puede volver atrás») y sobre todo por los propios árbitros que han participado en estas pruebas («Es un progreso muy importante. Esto es el fútbol-realidad... Además tiene virtudes pedagogicas para los jugadores. Sabe que son oídos por millones de espectadores y se concentran más en el juego», Alain Sars, árbitro del partido Marsella-Bastia, que portó un micrófono durante la emisión del partido realizada por televisión pública francesa TF-1).

${ }^{30}$ M. Robinson, Lo que el ojo no ve, Madrid, El País-Aguilar, 2001, 99-100. 


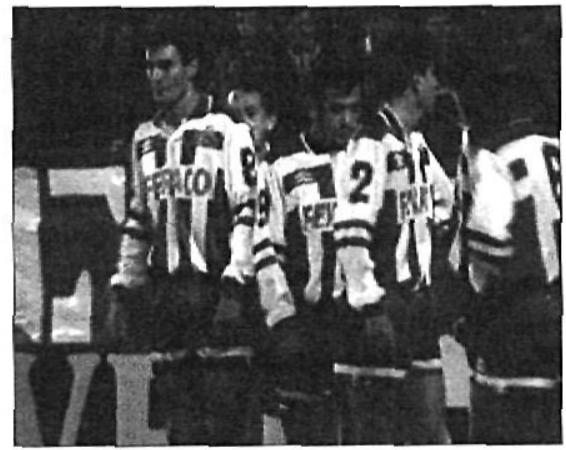

1. A: En la línea, «8», por favor

2. A: ((Pone su brazo derecho paralelo al pecho de $\mathbf{8}$ que ha comenzado a moverse ligeramente hacia atrás, girándose sobre su pierna derecha; 9, a continuación, un poco más adelantado mira hacia la izquierda, 5 vuelto hacia atrás, mira al arbitro, y $\mathbf{6}$ de perfil, también ligeramente más adelantado en el margen derecho de la imagen))

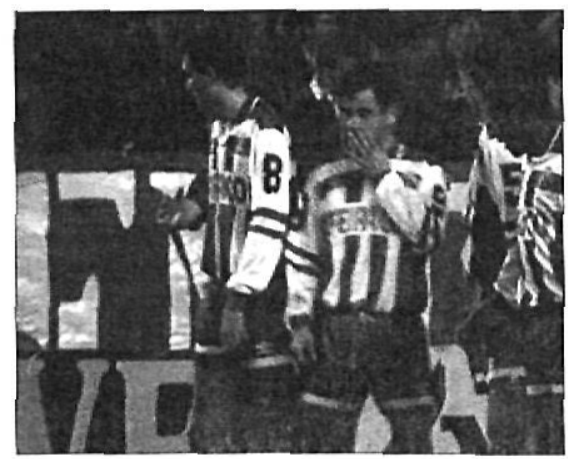

3. A: ((Parcialmente tapado por 3, que acaba de irrumpir en el cuadro, tiene su brazo derecho extendido hasta casi tocar con el brazo de un jugador que, asomando por el margen izquierdo de la imagen señala al frente. Las posiciones respectivas de $8,9,5$ y 6 prácticamente no han variado))

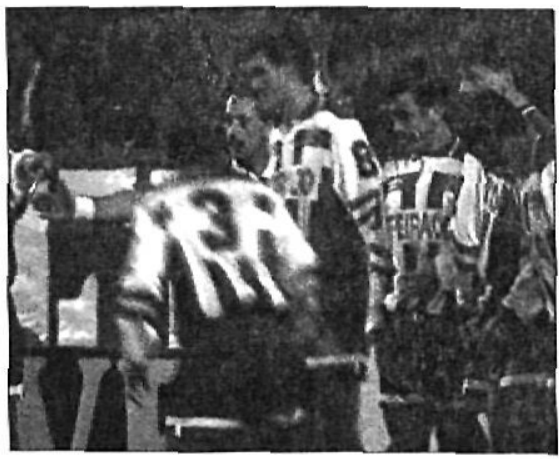


4. A: ((De frente en el centro de la imagen con el brazo extendido hacia el jugador que está adelantado a la izquierda de la imagen; $\mathbf{3}$, a la derecha. tapando a 9, se ha retraso unos pasos))

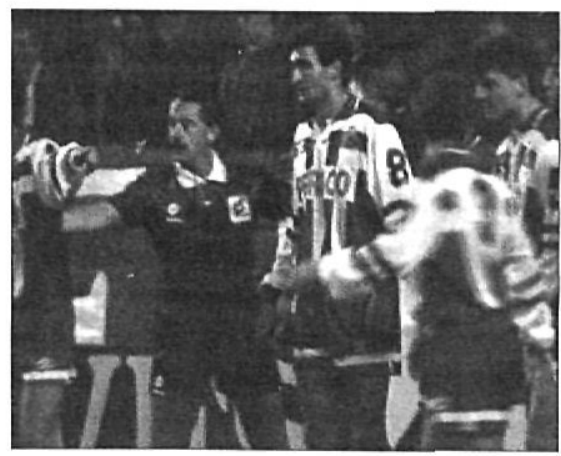

\section{A: En la línea}

((Mientras dice esto coge del brazo a 4 y lo retrasa, desplazándolo de izquierda a derecha en la imagen))

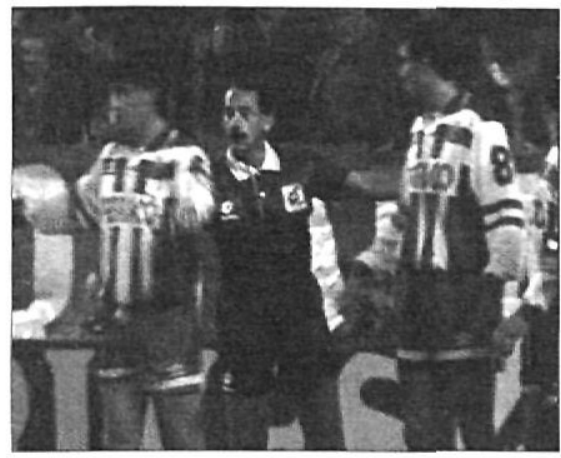

6. A: Ahí vale

((dicho con ligero tono interrogativo))

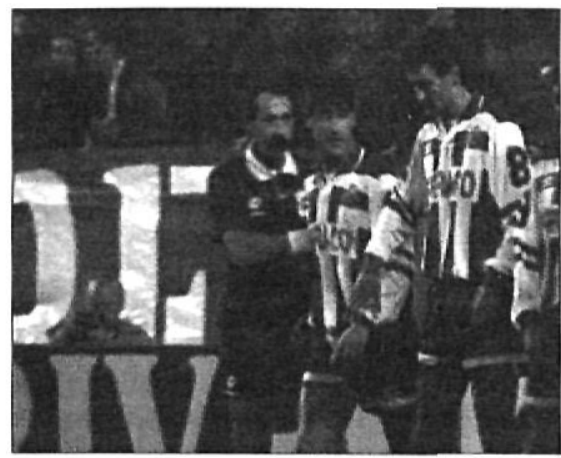


7. A: ((Tiene cogido del brazo a 4 , a su derecha; 8 , alineado a la derecha de 4 le coge de su otro brazo acercándolo hacia sí e intenta a su vez coger el brazo de 9. más a la derecha, para acercarlo también hacia sí))

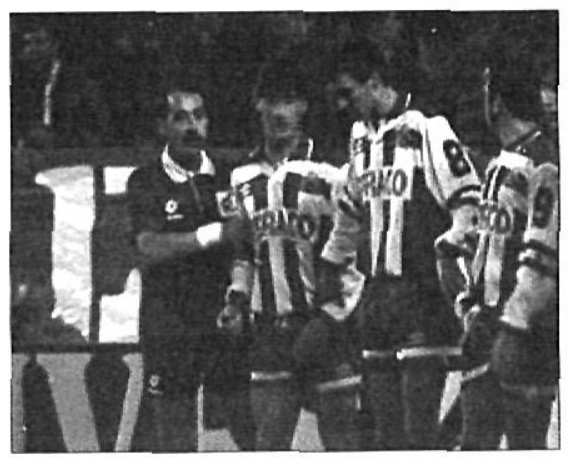

8. A: ( (Suelta el brazo de 4 y hace un gesto llevando su mano derecha de delante hacia atrás para indicar que se retrasen))

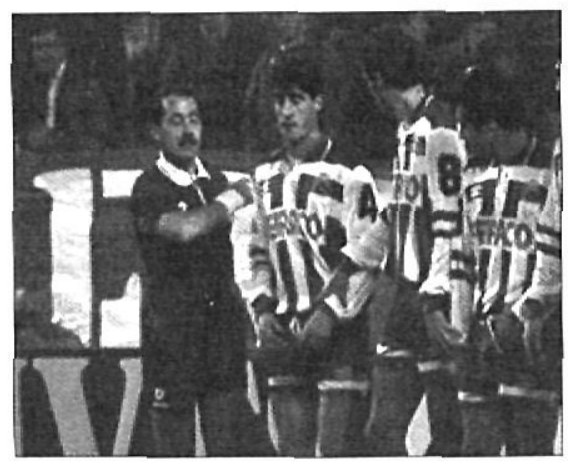

9. A: ((Sale repentinamente del extremo final de la línea y se dirige hacia el centro de la misma desplazándose de izquierda a derecha en la imagen; aparece $10 \mathrm{R}$ en el margen izquierdo))

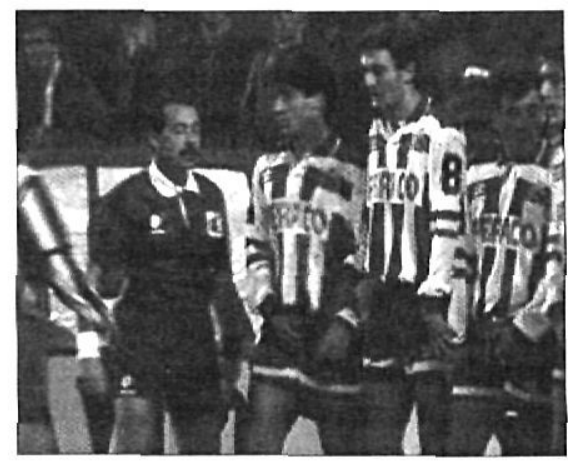


10. ((Alguien a quien no vemos grita: ¡Luis!))

11. 8: ¡No se mueve!

12. A: [iAtrás!]

13. 8: [iNo se mueve ni Dios!]

((dirigiendo el grito hacia su derecha))

14. A: ((Se ha puesto frente a 2 , que mira hacia el suelo, y con sus dos brazos extendidos hace un gesto indicándole que se mueva hacia atrás; mientras tanto 7 ha aparecido en el extremo inicial de la barrera))

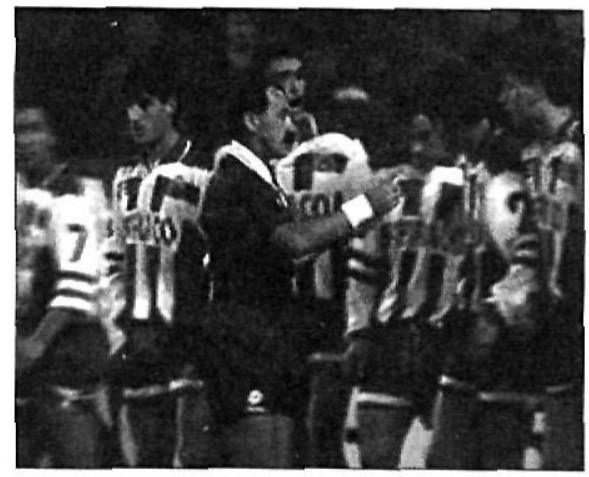

15. A: [Atrás]

((repite el gesto de extender los brazos pero separándolos un poco más entre sí))

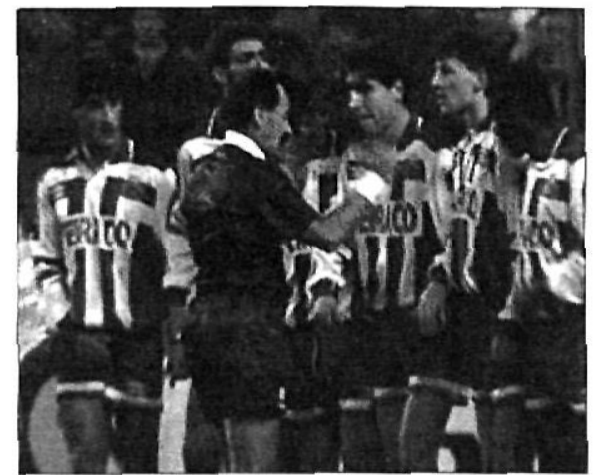

16. 8: [¡Eh Cuca!]

17. 8: ¡Aunque nos

18. A: ¡iChiss!!

((mandando callar a 6)) 


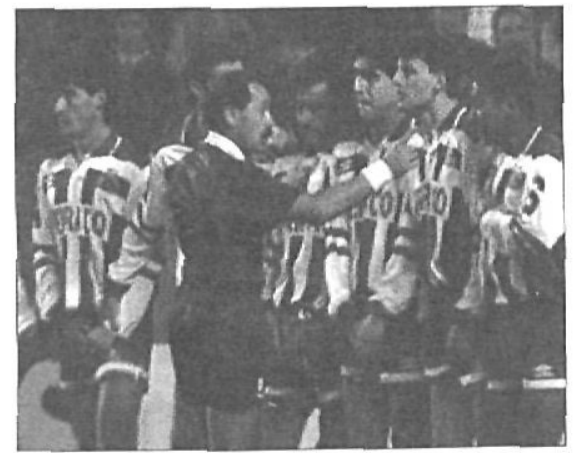

19. 8: mate, eh!!

20. A: [jAtrás!] ((repite el gesto con menos énfasis))

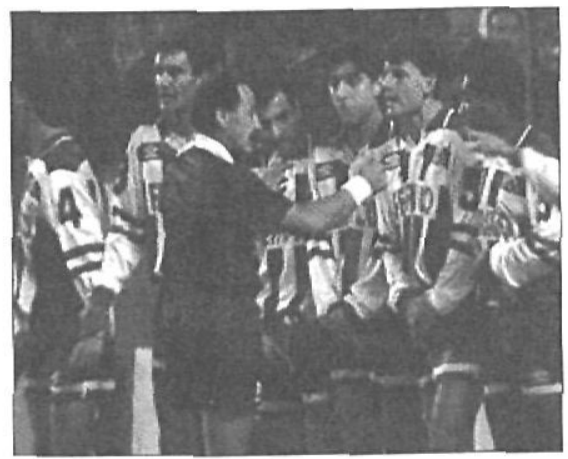

21. A: ¡iAtrás!!

((repite el mismo gesto con más énfasis, enfadado, mirando a 5))

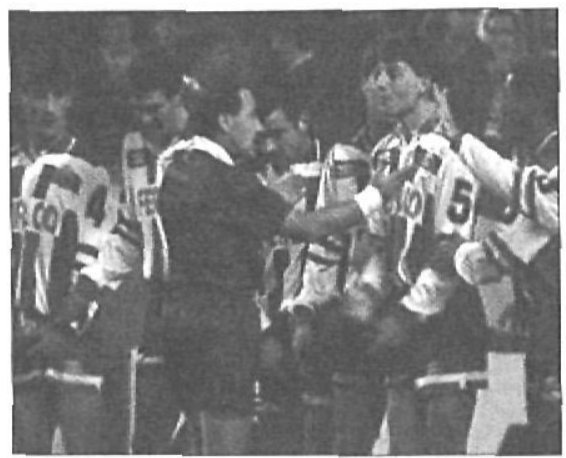

22. 8: ¡Aunque nos mate!

23. A: ¡ißHe dicho que atrás!!?

((con los dos brazos separados y extendidos hacia 9 y 2$)$ ) 


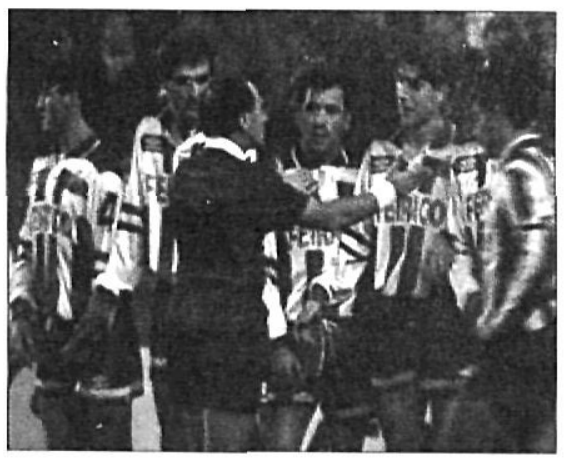

24. A: ¡Atrás!

((repitiendo el mismo gesto))

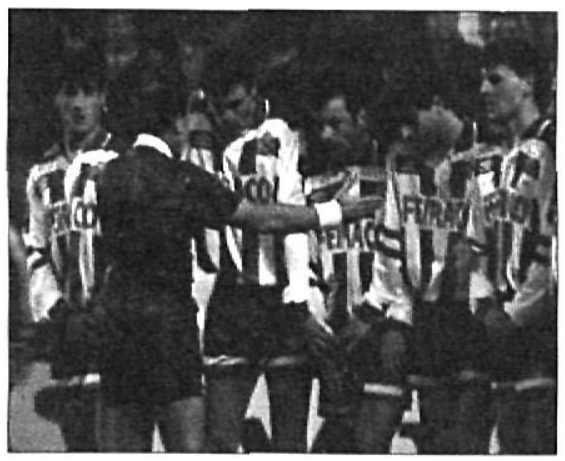

25. 8: ¡Cuidado con las [piernas eh!]

((Indicando con el brazo hacia abajo))

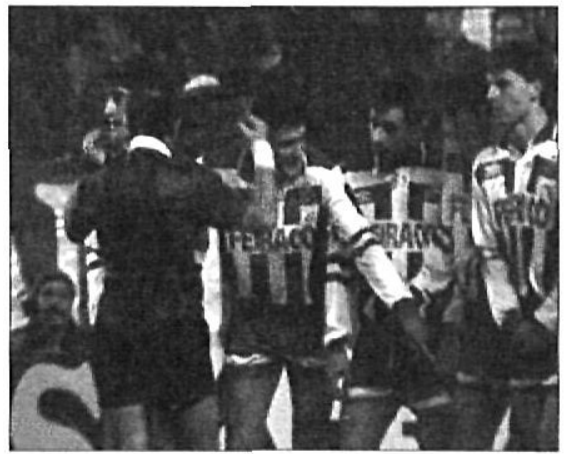

26. A: [Ahí]

((repite el mismo gesto con menos énfasis)) 


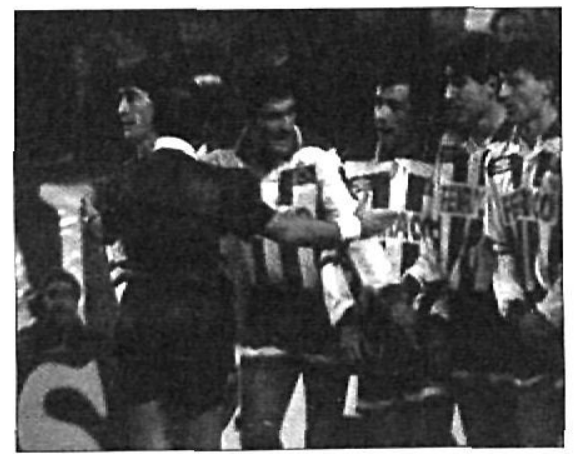

27. A: ¡Y de ahí no se mueve [nadie!]

((hace un gesto cruzando y descruzando horizontalmente sus brazos hasta extenderlos dejando las palmas de las manos hacia arriba))

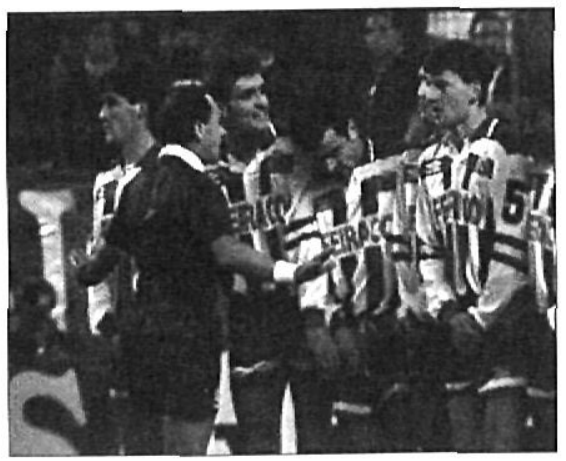

28. 8: [¡Oye!]

29. 8: ¿Ni Dios se mueve, eh por favor!

30. 4R: [Distancia para]

((entrando en cuadro a la izquierda de la imagen se dirige hacia $\mathrm{A}$ que le daba la espalda y se vuelve hacia él))

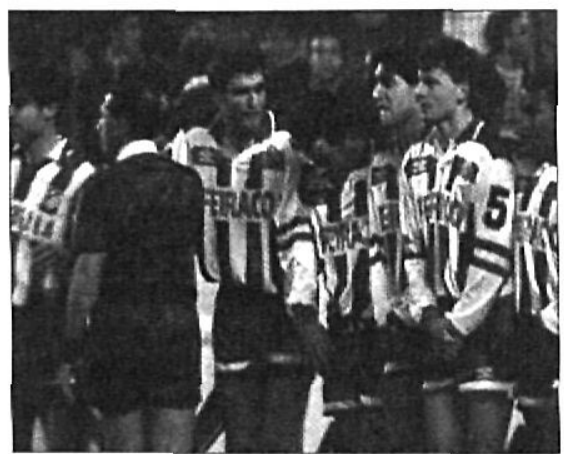




\section{8: [¡Por favor eh!]}

32. A: [Fuera] ( $($ Se vuelve hacia $\mathbf{4 R}$ y le hace un gesto echando la mano hacia atrás indicándole que se retire))

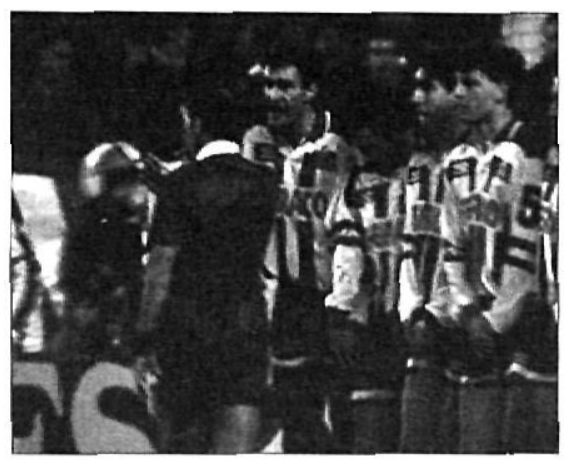

33. A: ((Se vuelve de nuevo hacia la barrera, de espaldas a la cámara, da media vuelta hasta ponerse de perfil, y finalmente se retira unos pasos hacia atrás andando de espaldas))

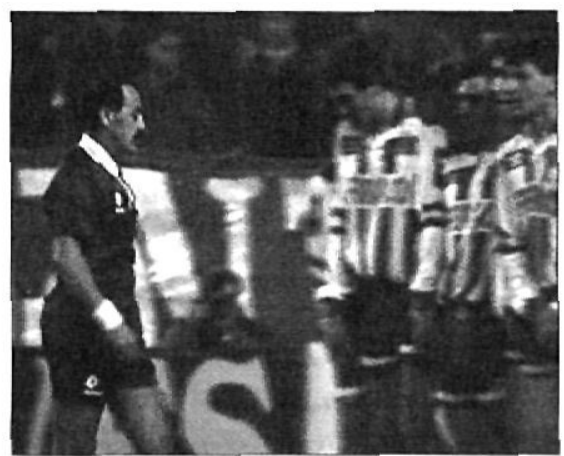

Vayan, en primer lugar, tres breves apuntes sobre el trabajo de transcripción:

1. Para transcribir en palabras los sonidos y movimientos sincrónicos que son audibles y visibles en la cinta de vídeo he empleado como herramienta de trabajo la versión 1.11 de Transana ${ }^{\odot}$ (1995-2002, propiedad de The Board of Regents of the University of Wisconsin System), un utilísimo paquete informático para la transcripción y el análisis de secuencias de vídeo digital, que puede descargarse gratuitamente en está página web: www.transana.org.

2. Para la extracción — en formato de «mapa de bits» (.bmp)—, edición y disposición (de arriba hacia abajo, a lo largo del eje vertical de la página) de los fotogramas insertos con los que he pretendido documentar algunos 
de los comportamientos no verbales más destacables de entre los descritos (verbalmente) en el texto de las transcripciones ${ }^{31}$ me he servido de una copia de evaluación del programa de captura de pantallas SnagIt ${ }^{\oplus 32}$.

3. Con el propósito ayudar al lector a poner en contexto práctico los efectos - potencialmente benéficos tanto como potencialmente maléficoslogrados en este caso por el procedimiento estándar de edición fotográfica empleado, me parece necesaria una observación al respecto de como han sido dispuestos los fotogramas de video en el contexto de la transcripción verbal. En un trabajo publicado en 1994 por la revista American Anthropologist, el antropólogo Charles Goodwin ha descrito algunos aspectos epistemológicamente relevantes del exhaustivo y minucioso trabajo ordinario de análisis pericial al que fueron sometidos, durante las vistas orales del primer juicio celebrado contra un grupo de oficiales del Departamento de Policía de Los Ángeles acusados de haber propinado una brutal paliza a un joven de color llamado Rodney King en marzo de 1991, todos y cada uno de los fotogramas de la breve secuencia videográfica de los hechos objeto de denuncia grabada casualmente por un videoaficionado y emitida previamente a la celebración del juicio por cadenas de televisión de todo el globo. El artículo se centra concretamente en el estudio de las técnicas de edición, ampliación, expansión y montaje fotográfico que fueron empleadas por los abogados de la defensa para tratar de congelar espacialmente y destacar visualmente determinados detalles secundarios previamente enterrados en el «fondo» de las imágenes en movimiento (como el cuerpo borroso y en rápido movimiento que surge al principio de la filmación desplazándose de izquierda a derecha desde el extremo izquierdo de la imagen e identificado aquí como «King corriendo hacia los agentes»), realzándolos luego gráficamente mediante técnicas de subrayado (dibujando círculos sobrepuestos de color blanco para acotar los límites entre objetos ambiguos) al objeto de destacarlos como las verdaderas «figuras» de la acción en las que el jurado debía fijar la vista ${ }^{33}$.

31 C. Heath y P. Luff, Technology in Action, Cambridge, UK, Cambridge University Press, $2000,27-30$, para el diseño de referencia de este formato de transcripción junto con algunas variantes -como la disposición horizontal alternativa de los fotogramas para ser leídos de izquierda a derecha de la página, a lo largo del eje definido por las líneas de la transcripción.

${ }^{32}$ La versión 6.1.2. Snaglt" es propiedad de la empresa Techsmith Corporation (copyright 19962002), y la versión de evaluación puede descargarse de forma gratuita en la página web: www.techsmith.com.

${ }^{33}$ «En los primeros segundos de la cinta, mientras que la cámara estaba todavía ligeramente desenfocada, King corría hacia los policías. En la cinta misma este suceso es difícil de apreciar: ocurre muy deprisa y es difícil discernirlo en medio de un campo perceptual oscuro y muy complejo habitado por un montón de eventos diferentes... Las imágenes visibles en la cinta son incluso más difíciles de ver a causa del movimiento del zoom de la cámara y por sus cambios de enfoque. En el primer juicio, uno de los abogados de la defensa consiguió trasladar a imágenes fotográficas los primeros fotogramas individuales de la cinta. Las fotografías fueron luego ampliadas en sus detalles, expandidas y pegadas unas junto a otras en secuencia dentro de un mural de un metro de largo que fue montado sobre un caballete y situado en la sala del juicio enfrente del jurado. La «saliencia» de King en estas imágenes fue amplificada mediante el uso de técnicas de subra- 
Por lo que respecto al contenido sustantivo en sí de la transcripción, ofreceré únicamente, para concluir, un breve apunte preliminar referente al tipo de cosas que nos permite ver la transcripción (esta transcripción) de un documento audiovideográfico (este documento) de una situación social real (esta situación).

En esta secuencia de vídeo vemos a una persona, el árbitro de fútbol, que viste de negro, que trata de llevar a cabo una tarea en presencia de otro grupo de personas, los jugadores de uno y otro equipo, a quienes pide colaborar en la misma. La transcripción y los fotogramas insertos documentan solamente algunos detalles audiovisuales de un segmento de la tarea que se pide llevar a cabo al árbitro: la parte de la misma consistente en «impedir que ninguno de los jugadores del equipo que ha hecho la falta sobrepase una imaginaria línea perpendicular al eje que forman el punto de medición con las líneas de banda, y por tanto paralela a la línea del centro del campo.»

La tarea descrita en la transcripción parece, a primera vista $\longrightarrow$, lo que es lo mismo, «en teoría»- muy sencilla. Una posible «glosa metodológica» del texto sería esta:

[El árbitro consigue impedir que ninguno de los jugadores del equipo que ha hecho la falta sobrepase una imaginaria línea perpendicular al eje que forman el punto de medición con las líneas de banda, y por tanto paralela a la línea del centro del campo]

Quienes sostienen que el «futuro» de las ciencias sociales reclama una profundización de su veta lógico-matemático-informática dirían incluso que se trata de una tarea puramente mecánica, esto es, mecanizable, por ejemplo, mediante el uso de una combinación de cámaras de vídeo y sistema experto informático de procesamiento de imágenes ${ }^{34}$. Ocurre sin embargo que la labor de «situar la barrera a la distancia reglamentaria para que pueda ejecutase el lanzamiento de la falta» implica un conjunto de fenómenos («En la línea, «8», por favor» [1. 1], «iijHe dicho que atrás!!!» [1. 23]; «iY de ahí no se mueve [nadie!]» [1. 27]; «iNi Dios se mueve, eh por favor!» [1.29], etc.), cuyo lenguaje de descripción razonada —esto es, los vocablos que empleamos para hacer referencia a la coreografía de gestos y sonidos que llamamos «conversación»- no ha sido aun asimilado como parte de la jerga técnica de la teoría físico-matemática de la medida ${ }^{35}$.

yado. El abogado de la defensa, a medida que explicaba los contenidos del mural, iba señalando, en la parte superior de las fotos, ciertos detalles, circulados con líneas blancas, con los que pretendía delimitar el cuerpo en movimiento de King.» (C. Goodwin, «Professional Vision», American Anthropologist, 1994, 96(3), 606-633, 622).

${ }^{34}$ Véase a este respecto R. Oudejans et. al., «Errors in judging 'offside' in football», Nature, 404, 2 March 2000; P. Gardner, «Should the referee's decision remain final?: Technology raises questions over the infallibility of the man in the middle», Soccer America, 1997, 52 (45), 17.

${ }^{35}$ Lo mismo puede sostenerse para el caso de la jerga jurídico-legal, que en su versión académica excluye la práctica totalidad del lenguaje coloquial de la vida ordinaria. La más somera inspección audiográfica del trabajo judicial in vivo de los árbitros de fútbol demuestra, a contrario, los absurdos analíticos en los que incurre necesariamente un lenguaje formal tan disparatadamente restrictivo. Sea el caso siguiente: «En un partido Zaragoza-Barcelona... Fernando Couto [defensa del Barcelona] recibió un guantazo a la salida de una jugada; Juanmi [portero del Zaragoza], 
«En la ejecución real de una práctica se involucra algo que no puede ser formulado ni en las instrucciones más detalladas. Por más cuidado que uno ponga en seguir, digamos, un manual de procedimientos de laboratorio, siempre necesitará tomar en cuenta mucho más de lo que previeron las instrucciones. Es este ubicuo «algo más» lo que delimita un campo de fenómenos investigables que no está tematizado en las exposiciones formales de los métodos científicos. Los científicos deben llegar a acuerdos con la singularidad de sus situaciones de investigación, y al hacerlo así se zambullen una y otra vez en circunstancias que requieren prácticas que sólo se especifican vagamente, cuando lo son, en las directrices metodológicas y en otra formulaciones de cómo se hace ciencia en general.» (Lynch, Livingston y Garfinkel, 1995: 165).

Y en última instancia, el hecho de que el detalle de las descripciones de la labor profesional que se documenta en la transcripción pueda ser extendido ad infinitum en una sucesión interminable de descripciones cada vez más precisas y más largas, es un indicador evidente del carácter lógica, matemática, e informáticamente intratable (no computable) de la labor en cuestión.

«En muchas ocasiones, el recurso a la tecnociencia [de la observación videográfica] no nos aportar ningún seguro para interpretar una acción mediante la aplicación de una regla. Incluso si visionamos las acciones dudosa a cámara lenta, la verdad es siempre relativa y no absoluta, como sucede con los «fuera de juego», el «juego peligroso», las «entradas duras», etc. $\mathrm{Ni}$ siquiera cuando se trata de decidir si el balon a traspasado o no la línea de gol -esto es, cuando se trata de juzgar la acción que constituye la razón de ser última del juego del fútbol- el visionado repetido de las imágenes no siempre nos permite resolver el contencioso... Descubrimos así, de forma experimental - pero al mismo tiempo natural porque, en el fondo, cada uno de nosotros ya lo sabe- aquello que de indecidible hay en el trabajo del árbitro, y que ninguna máquina podrá reemplazar al hombre porque somos seres interpretantes y la interpretación es una parte integral del juego.» (Coulon, 1998: 24).

\section{CONCLUSIÓN}

Es muy posible que, a través del estudio detallado de pequeños fenómenos, se dé verdaderamente un paso de gigante en la comprensión del modo como los humanos

inmediatamente después, cogío el balón y lo mandó lejos, y tras él salió toda la zaga. Pero Rafa Guerrero [el juez de línea] había visto el golpe, y avisó al árbitro [el colegiado Mejuto González]. Cuando éste se acerc6, Rafa Guerrero le dijo: «Penalti y expulsión». Y el árbitro le dijo: «Rafa, no me jodas.» (ROBINSON, 2001: 101-102). Al margen de constituir una patente falsificación de la realidad, la omisión deliberada de las expresiones coloquiales empleadas por los árbitros («Rafa, no me jodas») que cometen de manera rutinaria los propios colegiados en la redacción de los informes fácticos-legales al uso en este dominio profesional (vgr. las llamadas Actas Arbitrales) es, desde el punto de vista científico, un disparate descriptivo; esto es, un absurdo analítico. 
hacen las cosas y las clases de objetos que usan para construir y ordenar sus asuntos. (Sacks, 1984: 24).

Tras un siglo de innovaciones, desarrollos y disputas filosóficas y epistemológicas, la cuestión de los fundamentos metodológicos de las ciencias sociales se presenta, ciertamente, en nuestros días, dada la amplia variedad de perspectivas alternativas, bajo la forma de un problema de elección; o mejor, como una apuesta, pues ninguna toma de posición en este ámbito puede estar exenta de riesgos. Las diferentes opciones investigadoras disponibles están, efectivamente, expuestas a peligros de naturaleza recíproca ${ }^{36}$. Mientras que la inmensa mayoría que se decanta por la seguridad crítica, canónica, que ofrece el vasto corpus analítico de la teoría social no puede sino exponerse a los peligros de la denegación exterior, al rechazo mundano («El retrato que usted me ofrece de mi mundo no me resulta reconocible») ${ }^{37}$, el reducido aunque aguerrido batallón suicida que, hace ahora poco menos de medio siglo, apostó por despojar los procedimientos analíticos de la ciencia social de cualesquiera anclajes teóricos exteriores al mundo de la vida cotidiana, necesariamente ha de vérselas con la denegación y el descrédito interiores («QQué interés pueden tener estas investigaciones?», «Las descripciones etnometodológicas son pura banalidad»), cuando no con el reproche moral («Esos trabajos no son serios») o la prohibición implícita («iEsas cosas no se investigan!»).

En este artículo he sostenido que el trabajo de los árbitros de fútbol ofrece el equivalente a un «especimen experimental» específicamente adecuado para la investigación empírica (vg. «documental») sobre el qué y el cómo de los métodos de las ciencias sociales. No he pretendido con ello «entrever» un aspecto de lo general a través de un análisis de particulares. Lo contrario es más bien cierto: he tratado de revelar lo que de particular hay en cada muestra particular de razonamiento, inducción, previsión, ordenamiento, etc. Lo específico del conocimiento experto, y en particular de aquello que llamamos la visión profesional («tener ojo para algo», «a ojo de buen cubero», «ver en torno») es justamente eso: el interés natural por los detalles concretos (que no «microscópicos») del objeto de estudio y el carácter inexcusable, ineludible e irremediablemente local de toda pesquisa. Aun de la más abstracta.

${ }^{36}$ Como ha sostenido el sociólogo Michael Lynch, si bien «pocos de entre los numerosos participantes en el popular campo de los estudios culturales se hallan expuestos a los riesgos que azotan a la etnometodología, y que provienen de la aparente carencia de punto de vista normativo o epistemológico independiente de las prácticas investigadas» lo cierto es que los estudios culturales "están sin embargo expuestos a riesgos de carácter recíproco, derivados en su caso del intento de establecer un punto de vista crítico y escéptico desde el cual desvelar el carácter construido de los hechos y las leyes científicas.» (LYNCH, 1999: 222).

${ }^{37}$ El caso canónico del descrédito exterior que sufren las ciencias sociales nos lo ofrecen las reacciones de los científicos naturales a los retratos que de su mundo y de su trabajo hacen filósofos, historiadores, sociólogos y antropólogos de la ciencia. «A menudo los científicos sienten aversión por lo que los no científicos dicen de la ciencia... Los estudios sociales de la ciencia y la filosofía de la ciencia tienden a ser abstractos, a ocuparse de acontecimientos históricos bien conocidos, o ejemplos remotos que no tienen relación alguna con lo que sucede diariamente en un laboratorio ni con las interacciones que se producen entre los científicos cuando persiguen sus fines.» (SALK, 1995: 17; véase también HERITAGE, 1984: 300). 


\section{BIBLIOGRAFÍA}

AGRÉ, P. (1998): «Hazards of Design: Ethnomethodology and the Ritual Order of Computing», ponencia presentada en la Conferencia Anual de la Asociación Americana de Sociología, Sesión sobre Etnometodología: estudios híbridos sobre el trabajo, San Francisco, agosto.

ARENDT, H. (1995): «El pensar y las reflexiones morales» [1971], en H. Arendt, De la historia a la acción, Barcelona, Paidós, 110-137.

Aresu, M.; BuCARelli, A., y Marongiu, P. (1979): «Preliminary investigation of the authoritarian tendencies in a group of sport referees», International Journal of Sport Psychology, 10, 42-51.

AtienZA, M. (1993): Tras la justicia, Barcelona, Ariel.

AtKinson, J. M. (1986): Our Masters» Voices, Londres, Routledge.

Auslander, P. (1999): «Legally Live: Law, Performance, Memory», en Auslander, Liveness. Performance in a Mediatized Culture, Londres, Routledge, 112-157.

BAR-ELI, M., et. al. (1995): «A crisis-related analysis of perceived referees» behavior in competition», Journal of Applied Sport Psychology, 7(1), 63-80.

Boltanski, L. y Thévenot, L. (1991): De la justification, Paris, Gallimard.

- y E. Chiapello (2002): El nuevo espíritu del capitalismo, Madrid, Akal.

BURNS, R. (1987): «Applying the soccer referee»s match techniques to the rearing of children», Soccer Journal, 32(6), 51-54.

BYRNE, E. (1981): «Warn, caution or eject? Referees must enforce not only the laws but also the spirit behind the laws of soccer", Soccer Corner, 5(1), 72-75.

- (2000): «Interpreting the rules: referees often must consider several criteria when making a call», Soccer Journal, marzo-abril, 43-44.

Chase, W. G. y Simon, H. A. (1973): «Perception in Chess», Cognitive Psychology, 4, 55-81.

Colwell, S. (1998): «Pressure Points: Officiating in the 1990s», en Singer \& Frielander»s Review 1997-1998 Season, Centre For Research Into Sport and Society, University of Leicester.

- (1999): «Stalking Referees: Resolving Refereeing Problems», en Singer \& Frielander»s Review 1998-1999 Season, Centre For Research into Sport and Society, University of Leicester.

- (2000): «The «Letter» and the «Spirit»: Football Laws and Refereeing in the TwentyFirst Century», Soccer \& Society, 1(1), 201-214.

- (2001a): «The Man in the Middle: An Interview with the FA Premier League Referees» Officer, Phil Don, en Singer \& Frielander's Review 2000-2001 Season, Centre For Research Into Sport and Society, University of Leicester, 46-49.

- (2001b): «Public Enemy N. ${ }^{\circ} 1$ !»: Television, Commentators and Our Perceptions of Referees», en Singer \& Frielander's Review 2000-2001 Season, Centre For Research Into Sport and Society, University of Leicester, 2001, 50-55.

Coulon, A. (1998): «Le football comme spectacle: le plaisir de l»arbitraire», Communications, 67, 25-32.

CyruS, T. (2000): «Resolute Ambivalence: Why Judiciaries Do Not Institutionalize Their Decission Support Systems», International Review of Law, Computers \& Technology, 14 (3), 297-317.

Dip, C., et. al. (1993): «Analysis of the work rates and heart rates of association football referees», British Journal of Sports Medicine, 27(3), 193-196.

GaLISON, P. (1987): How Experiments End, Chicago, IL, Chicago University Press, 1987.

GARDNER, P. (1997): «Is the gavel mightier than the whistle? Dragging the game and its referees into the courts", Soccer America, 52(10), 10. 
GarfinKel, H. (1984): «Some Rules of Correct Decisions that Jurors Respect» [1967], en H. Garfinkel, Studies in Ethnomethodology, Londres, Polity, 1984, 104-115.

- (1991): «Respecification: evidence for locally produced, naturally accountable phenomena of order*, logic, reason, meaning, method, etc. in and as of the essential haecceity of immortal ordinary society, (I) - an announcement of studies», en G. Button (ed.), Ethnomethodology and the Human Sciences, Cambridge, UK, Cambridge University Press, 10-19.

- (2002): Ethnomethodology»s Program, Lanham, Maryland, Rowman and Littlefield.

- (ed.) (1986): Ethnomethodological Studies of Work, Londres, Routledge \& Keegan Paul.

- LYNCH, M., y Livingston, E. (1981): «The Work of a Discovering Science Construed with Materials from the Optically Discovered Pulsar», Philosophy of the Social Sciences, 11, 131-58.

GINZBURG, C. (1992): «Indicios. Raíces de un paradigma de inferencias indiciales», en Ginzburg, Mitos, emblemas, indicios, Barcelona, Gedisa, 138-175.

Goodwin, C. (1995): «Seeing in Depth», Social Studies of Science, 25(2), 237-274.

HABERMAS, J. (1998): Facticidad y validez, Madrid, Trotta.

HACKING, I. (1996): Representar e intervenir [1983], Barcelona, Paidós.

HAGAN, P. (1997): «Positioning and movement: one referee»s views», Football Referee, 12 de octubre.

Henham, R. (2000): «On the Philosophical and Theoretical Implications of Judicial Decision Support Systems", International Review of Law, Computers \& Technology, 14 (3), 283-297.

HERITAGE, J. (1984): Garfinkel and Ethnomethodology, Londres, Polity.

- y Clayman, S. (2002): The News Interview, Nueva York, Cambridge University Press.

HiLL, G. (1977): «Game control: the player's top priority for referees», Soccer Monthly, $3(10), 8-9$.

IBÁÑEZ, J. (1985): «Las medidas de la sociedad», Revista Española de Investigaciones Sociologicas, 29, 85-127.

IZQUIERDO, A. J. (2003): «La tercera juventud de Harold Garfinkel: una nueva invitación a la sociología», Anduli. Revista Andaluza de sociología, en prensa.

JASANOFF, S., y LYNCH, M. (1998): «Contested Identities: Science, Law and Forensic Practice», Social Studies of Science, 28, 675-86.

JohnstON, L., y MCNAUGHTON, L. (1994): «The physiological requirements of soccer refereeing», Australian Journal of Science \& Medicine in Sport, 26 (3/4), 67-72.

Jonsen, A. R., y Toulmin, P. (1988): «Perjury: The Case of Equivocation», en Jonsen y Toulmin, The Abuse of Casuistry, Berkeley, CA, University of California Press, 194-215.

KULA, K. (1980): Las medidas y los hombres [1970], Madrid, Siglo XXI.

Lemieux, C. (2000): Mauvaise presse, París, Métailié.

LIVINGSTON, E. (1986): The Ethnomethodological Foundations of Mathematics, Londres, Routledge.

LYNCH, M. (1999): «Silence in Context: Ethnomethodology and Social Theory», Human Studies, 22, 211-233.

- (1987): Art and Artifact in Laboratory Science, Londres, Routledge and Kegan Paul.

- Livingston, E., y GarfinkEL, H. (1995): «El orden temporal en el trabajo de laboratorio» [1983], en J. M. Iranzo, R. Blanco, T. González de la Fé, C. Torres y A. Cotillo (coords), Sociología de la ciencia y la tecnología, Madrid, CSIC, 163-185.

Luff, P.; Hindmarsh, J., y HEATH, C. (2000): Workplace Studies, Cambridge, UK, Cambridge University Press. 
MEHAN, H. (2001): «Un estudio de caso en la política de la representación», en J. Lave y S. Chaiklin, Estudiar la práctica, Buenos Aires, Amorrortu, 262-290.

MaYnARD, D. W., y MANZo, J. (1993): «On the Sociology of justice: Theoretical notes from an actual jury deliberation», Sociological Theory, 11, 171-193.

MirowsKI, P. (1992): «Looking for Those Natural Numbers: Dimensionless Constants and the Idea of Natural Measurement», Science in Context, 5(1), 165-188.

MORENILlA, J. (2002): «La brutal paliza de cada semana. Los árbitros no profesionales siguen víctimas de la falt de seguridad y las agresiones sin que el fútbol encuentre remedio a su drama», diario EL PAÍS, Madrid, 18 de noviembre, p. 54.

- (2003): «El árbitro en directo», diario EL PAÍS, Madrid, 6 de enero, p. 50.

NAGEL, E. (1968): La estructura de la ciencia [1961] Barcelona, Paidós.

NIETo, A. (2000): El arbitrio judicial, Barcelona, Ariel.

PALOMAR, A. (2000): «La profesionalización del arbitraje en el ámbito deportivo: una realidad controvertida (Su concreción en el ámbito del fútbol)», en Palomar (ed.), Cuestiones de fútbol profesional, Madrid, Real Federación Española de Fútbol, 42159.

PÉrez Abellán, F. (2002): Alcácer, punto final, Barcelona, Ediciones Martínez Roca.

POPPER, K. (1977): La lógica de la investigación científica [1959] Madrid, Técnos.

RAMOS MARCOS, J. (2001): La ley del fútbol, Madrid, La Esfera Libros.

Robinson, M. (2001): Lo que el ojo no ve, Madrid, El País-Aguilar.

SACKS, H. (1984): «Notes on Methodology», en J. M. Atkinson y J. C. Heritage (eds.), Structures of Social Action, Cambridge, UK, Cambridge University Press, 21-27.

SALK, J. (1995): «Introducción» [1979], en B. Latour y S. Woolgar, La vida en el laboratorio, Madrid, Alianza, 17-20.

SEGUROLA, S. (2002): «Conflicto en el videomarcador. La FIFA incumple sus propias reglas al autorizar que se emitan en los estadios imágenes de los partidos mientras se juegan», diario EL PAÍS, Madrid, 5 de junio.

SHAPIN, S., y SCHAFFer, S. (1985): Leviathan and the Air-Pump, Princeton, NJ, Princeton University Press.

Simon, H. A. (1986): «De la racionalidad sustantiva a la racionalidad procesual», en F. Hahn y M. Hollis (eds.), Filosofía y teoría económica, México DF, Fondo de Cultura Económica, 130-171.

Suchman, L. (1987): Plans and Situated Action, Cambridge, UK, Cambridge University Press.

TAYLOR, A., y DANIEL, J. (1987): «Sources of stress in soccer officiating: an empirical study», en Reilly, et al. (eds.), Science and football: proceedings of the First World Congress of Science and Football, Liverpool, 12-17 de abril, 538-544.

TRAVERS, M. (2001): «Law in Action: An Ethnomethodological Perspective», ponencia presentada en el V Joint Meeting LSA/ISA RCSL, Budapest, Hungría, 4-7 julio.

- y MANzo, J. (eds.) (1997): Law in Action. Ethnomethodological and Conversation Analytic Approaches to Law, Aldershot, UK, Ashgate-Dartmouth.

VAN KOLFSCHOOTEN, F. (1998): «Cool it, ref! Rushing to follow the action is the cause of many mistakes», New Scientist, vol. 159, n. $^{\circ} 2141,12$.

VERDÚ, V. (1980): «Demiurgia del árbitro», en Verdú, El fútbol. Mitos, ritos, símbolos, Madrid, Alianza.

VILLALBA, J. M. (2001a): «El arbitraje o la vocación incomprendida», diario EL PAIS, Madrid, 12 marzo, p. 58.

- (2001b): «Ayuda mental para los árbitros», diario EL PAÍS, Madrid, 13 de agosto, p. 44.

WENGER, E. (2001): Comunidades de práctica, Barcelona, Paidós. 
Zeleznikow, J. (2000): «Building Decision Support Systems in Discretionary Legal Domains», International Review of Law, Computers \& Technology, 14 (3), 341-357. ZÚNIIGA, R. (2002): «Vídeos para la justicia», diario EL PAIS (suplemento NEGOCIOS), domingo 24 de febrero, p. 12.

\title{
RESUMEN
}

La práctica del «buen juicio» realiza implícitamente una competencia cognitiva bajo la forma expresa del desempeño de una capacidad moral. La específica mezcla de precisión y prudencia que llamamos «juicio experto» es susceptible de ser natural y públicamente examinada en y como los detalles sensibles en los que se concreta la situación social en la que se halla singularmente inmerso quien juzga. El enjuiciamiento público in vivo e in situ del sentido de una situación social concreta es una tarea técnica particularmente distintiva del trabajo profesional de los árbitros de fútbol. Se ofrece aquí una descripción cuidadosa de un cierto documento que plasma en detalles audio-videográficos públicamente atestiguables la tarea arbitral que consiste en colocar a los jugadores en un punto geográfico concreto del terreno de juego, tal como especifican de manera teórica las normas del reglamento deportivo, como «alterno etnometodológico» de la descripción analítico-formal de los métodos sociológicos de medición social.

\begin{abstract}
The practice of «sensible judgement» implicitly realizes a cognitive capacity under the explicit performance of a moral competence. The specific mix of accuracy and balance that we call «expert judgement» is naturally and publicly witnessable in and as the sensible details that make the singular social situation in which she who judges is concretely enmeshed. The in vivo and in situ public assessment of a concrete social situation is a technical task particularly distinctive of the professional work of football (soccer) referees. In this work a careful description of the details of a document that renders in publicly inspectable audio-videographic detail the particular refereeing task of locating players in a concrete geographic point of the playing field as theoretically specified by the rules of the game is offered as a specific «ethnometodological alternate» for the formal-analytic description of sociological methods of measurement.
\end{abstract}

